OPEN ACCESS

Edited by:

Maya Koronyo-Hamaoui, Cedars Sinai Medical Center,

United States

Reviewed by:

Francesca Gilli,

Dartmouth College, United States

Tobias Zrzavy,

Medical University of Vienna, Austria

*Correspondence:

Aaron J. Johnson

Johnson.Aaron2@mayo.edu

Specialty section: This article was submitted to

Multiple Sclerosis and

Neuroimmunology,

a section of the journal

Frontiers in Immunology

Received: 16 June 2021 Accepted: 09 August 2021 Published: 30 August 2021

Citation:

Goddery EN, Fain CE, Lipovsky CG, Ayasoufi K, Yokanovich LT, Malo CS, Khadka RH, Tritz ZP, Jin F, Hansen MJ and Johnson AJ (2021) Microglia and

Perivascular Macrophages Act as Antigen Presenting Cells to Promote

CD8 T Cell Infiltration of the Brain.

Front. Immunol. 12:726421.

doi: 10.3389/fimmu.2021.726421

\section{Microglia and Perivascular Macrophages Act as Antigen Presenting Cells to Promote CD8 T Cell Infiltration of the Brain}

\author{
Emma N. Goddery ${ }^{1,2}$, Cori E. Fain ${ }^{1,2}$, Chloe G. Lipovsky ${ }^{1,2}$, Katayoun Ayasoufi ${ }^{1}$, \\ Lila T. Yokanovich ${ }^{1,2}$, Courtney S. Malo ${ }^{1,2}$, Roman H. Khadka ${ }^{1,2}$, Zachariah P. Tritz ${ }^{1,2}$, \\ Fang Jin ${ }^{1}$, Michael J. Hansen ${ }^{1}$ and Aaron J. Johnson ${ }^{1,3,4 *}$ \\ 1 Department of Immunology, Mayo Clinic, Rochester, MN, United States, ${ }^{2}$ Mayo Clinic Graduate School of Biomedical \\ Sciences, Mayo Clinic, Rochester, MN, United States, ${ }^{3}$ Department of Neurology, Mayo Clinic, Rochester, MN, United States, \\ ${ }^{4}$ Department of Molecular Medicine, Mayo Clinic, Rochester, MN, United States
}

CD8 T cell infiltration of the central nervous system (CNS) is necessary for host protection but contributes to neuropathology. Antigen presenting cells (APCs) situated at CNS borders are thought to mediate $\mathrm{T}$ cell entry into the parenchyma during neuroinflammation. The identity of the CNS-resident APC that presents antigen via major histocompatibility complex (MHC) class I to CD8 T cells is unknown. Herein, we characterize $\mathrm{MHC}$ class I expression in the naiive and virally infected brain and identify microglia and macrophages (CNS-myeloid cells) as APCs that upregulate $\mathrm{H}-2 \mathrm{~K}^{\mathrm{b}}$ and $\mathrm{H}$ $2 \mathrm{D}^{\mathrm{b}}$ upon infection. Conditional ablation of $\mathrm{H}-2 \mathrm{~K}^{\mathrm{b}}$ and $\mathrm{H}-2 \mathrm{D}^{\mathrm{b}}$ from CNS-myeloid cells allowed us to determine that antigen presentation via $\mathrm{H}-2 \mathrm{D}^{\mathrm{b}}$, but not $\mathrm{H}-2 \mathrm{~K}^{\mathrm{b}}$, was required for CNS immune infiltration during Theiler's murine encephalomyelitis virus (TMEV) infection and drives brain atrophy as a consequence of infection. These results demonstrate that CNS-myeloid cells are key APCs mediating CD8 T cell brain infiltration.

Keywords: microglia, antigen presentation, TMEV, viral infection, MHC class I, perivascular macrophage, CD8 T cell, atrophy

\section{INTRODUCTION}

$\mathrm{T}$ cells play essential roles in host protection from CNS infection; yet, infiltrating $\mathrm{T}$ cells induce potent immunopathology during neuroinflammation associated with infections and autoimmunity (1-7). Recent studies suggest that dysregulated $\mathrm{T}$ cell brain infiltration may also contribute to pathology in neurodegenerative diseases (8-10). Rediscovery of the glymphatic system in the CNS has allowed for improved understanding of how $\mathrm{T}$ cells are primed and activated against CNSderived antigens $(11,12)$. Conceivably, $\mathrm{T}$ cells encounter cognate antigen once it has drained to the deep cervical lymph node, where antigen presenting cells (APCs) prime naïve T cells $(13,14)$. However, activated $\mathrm{T}$ cells are restimulated by local APCs to infiltrate across the blood brain barrier (BBB) into the parenchyma. This crucial process is not fully defined (15-17).

CNS antigen presentation has been primarily studied in the experimental autoimmune encephalomyelitis (EAE) model of multiple sclerosis in which activated autoantigen-specific CD4 
$\mathrm{T}$ cells migrate to the CNS, infiltrate the parenchyma, and mediate disease development (18). Local APCs are crucial for CD4 $\mathrm{T}$ cell infiltration, and this role is primarily attributed to $\mathrm{CD}_{11 \mathrm{c}^{+}}$dendritic cells (19-21). However, microglia and brain macrophages (CNS-myeloid cells) become fully competent APCs during CNS infection models, and the contribution of local APCs in potentiating CD8 $\mathrm{T}$ cell infiltration of the CNS remains undefined (22-25). One viral model commonly used to assess immune infiltration of the brain is Theiler's murine encephalomyelitis virus (TMEV), a neurotropic murine picornavirus. Immune infiltration mediates clearance of TMEV in C57BL/6 mice, but this results in cognitive deficits and brain atrophy (26-28). However, mice deficient in CD8 T cells or lacking certain MHC class I haplotypes are unable to clear TMEV from the CNS, resulting in virus-induced demyelinating disease (29-32). CD8 T cell activation, brain infiltration, and viral clearance are dependent on recognition of the immunodominant TMEV capsid protein-derived peptide VP2 $2_{121-130}$ presented in the $\mathrm{H}-2 \mathrm{D}^{\mathrm{b}}$ MHC class I molecule $(13,30$, $31,33)$. The highly reproducible nature of this CD8 $\mathrm{T}$ cell response enables in vivo analysis of antigen presentation requirements for lymphocyte infiltration of the brain.

Here, we sought to define the role of local antigen presentation in CD8 $\mathrm{T}$ cell infiltration of the virally infected CNS. Activated CNS-myeloid cells upregulate MHC class I and localize near hippocampal vasculature during TMEV infection, a prime location to interact with CD8 $\mathrm{T}$ cells attempting to cross the $\mathrm{BBB}$. Using transgenic C57BL/6 mice in which one of the two MHC class I molecules is deleted in CNS-myeloid cells, we uncovered differential requirements for $\mathrm{H}-2 \mathrm{~K}^{\mathrm{b}}$ and $\mathrm{H}-2 \mathrm{D}^{\mathrm{b}}$ molecules in promoting immune infiltration of the brain. We further show that antigen presentation by CNS-myeloid cells promotes brain atrophy resulting from the CD8 T cell response against TMEV.

\section{EXPERIMENTAL MODEL AND SUBJECT DETAILS}

\section{Mice}

C57BL/6J (B6; Stock No. 000664), B6.PL-Thy1/CyJ (Thy1.1; Stock No. 000406), B6.129P2(Cg)-Cx3cr1tm2.1(cre/ERT2)Litt/ WganJ (CX3CR1creER, Stock No. 021160), and B6.129P2(Cg)Cx3cr1 $1^{\text {tm1Litt } / J}$ (CX3CR $1^{\text {GFP/GFP }}$; Stock No. 005582) were acquired from the Jackson Laboratories (Bar Harbor, ME). Following shipment, mice were acclimated for at least one week prior to use. CX3CR1-creER ${ }^{\mathrm{T} 2} \mathrm{x} \mathrm{K}^{\mathrm{b} \text { fl/fl }}$ animals $\left(\mathrm{CX} 3 \mathrm{CR} 1^{\mathrm{cre}} / \mathrm{K}^{\mathrm{b}}\right)$ and CX3CR $1^{\text {creER }} \times \mathrm{D}^{\mathrm{b}}$ fl/fl animals $\left(\mathrm{CX} 3 \mathrm{CR} 1^{\text {cre }} / \mathrm{D}^{\mathrm{b}}\right.$ ) were generated in house as described below. For experiments involving tamoxifen-mediated cre activation, male and female mice between 4 and 6 weeks of age received tamoxifen (or corn oil) prior to experimental use at 10-12 weeks of age. For all other experiments, male and female mice between 5-12 weeks of age were used. 7-14-week-old female or male mice were used for donors in bone marrow chimera experiments. Heterozygous $\mathrm{CX} 3 \mathrm{CR} 1^{\mathrm{GFP} /+}$ were used for experiments. All mice were group housed under controlled temperature and humidity with a 12-h light/dark cycle. Mice were provided ad libitum access to food and water. All animal experiments were approved by and performed in accordance with the Mayo Clinic Institutional Animal Care and Use Committee and the National Institutes of Health guidelines.

\section{Generation of Transgenic CX3CR $1^{\text {creER }} \mathrm{x}$ $\mathrm{K}^{\mathrm{b} f \mathrm{f} / \mathrm{fl}}$ and CX3CR1 $1^{\text {creeR }} \times \mathrm{D}^{\mathrm{b} \text { fl/fl }}$ Mouse \\ Strains}

Transgenic $\mathrm{H}-2 \mathrm{~K}^{\mathrm{b}} \operatorname{LoxP}\left(\mathrm{H}-2 \mathrm{~K}^{\mathrm{b}} \mathrm{fl} / \mathrm{fl}\right)$ and $\mathrm{H}-2 \mathrm{D}^{\mathrm{b}} \operatorname{LoxP}\left(\mathrm{H}-2 \mathrm{D}^{\mathrm{b}} \mathrm{fl} / \mathrm{fl}\right)$ mice were both generated by our group as previously described (13, 14). In brief, LoxP sites were inserted into $K^{b}$ and $D^{b}$ transgenes which were previously cloned via site-directed mutagenesis. After $\mathrm{K}^{\mathrm{b}}$ or $\mathrm{D}^{\mathrm{b}}$ transgene insertion to C57BL/6J mice (Stock No. 000664) by the Mayo Clinic Transgenic Mouse Core (Rochester, MN), animals were backcrossed onto MHC class I deficient animals $\left(\mathrm{H} 2 \mathrm{~K}^{\mathrm{b}} \mathrm{D}^{\mathrm{b}} \mathrm{KO}\right)$ resulting in mice in which the transgenic $\mathrm{K}^{\mathrm{b}}$ or $\mathrm{D}^{\mathrm{b}}$ was the only MHC class I molecule expressed. CX3CR $1^{\text {creER }}$ (Stock No. 021160) animals were crossed to MHC class I deficient animals $\left(\mathrm{H}-2 \mathrm{~K}^{\mathrm{b}} \mathrm{D}^{\mathrm{b}} \mathrm{KO}\right)$ for at least three generations for the strain to be MHC class I deficient (The Jackson Laboratory, Bar Harbor, ME). MHC class I deficient CX3CR $1^{\text {creER }}$ animals were then crossed to the $\mathrm{K}^{\mathrm{b}}$ LoxP mouse to generate $\mathrm{CX} 3 \mathrm{CR} 1^{\mathrm{creER}} / \mathrm{K}^{\mathrm{b}} \mathrm{cKO}$ animals, or the $\mathrm{D}^{\mathrm{b}}$ LoxP mouse to generate CX3CR $1^{\text {creER }} / \mathrm{D}^{\mathrm{b}} \mathrm{cKO}$ animals. Tail DNA screening was performed using polymerase chain reaction for cre using primer sequences recommended by Jackson Laboratory (Forward: AAG ACT CAC GTG GAC CTG CT; Mutant, Reverse: CGG TTA TTC AAC TTG CAC CA; WT, Reverse: AGG ATG TTG ACT TCC GAG TTG). Flow cytometry was used to confirm presence of the CX3CR1creER transgene via YFP reporter expression and class I deficiency using $\mathrm{K}^{\mathrm{b}}$ and $\mathrm{D}^{\mathrm{b}}$ surface expression. Mice were considered $\mathrm{cKO}$ if they were positive for the cre transgene by PCR and flow cytometry, and tamoxifen injection successfully mediated deletion of $\mathrm{K}^{\mathrm{b}} / \mathrm{D}^{\mathrm{b}}$ surface protein on CX3CR1-expressing cells.

\section{METHOD DETAILS}

\section{Tamoxifen Administration}

Tamoxifen (Sigma-Aldrich, St. Louis, MO) was administered in corn oil (Sigma-Aldrich, St. Louis, MO) at a concentration of $20 \mathrm{mg} / \mathrm{mL}$. Tamoxifen was dissolved in corn oil by shaking overnight at $37^{\circ} \mathrm{C}$ in the dark. Animals were administered $75 \mathrm{mg} / \mathrm{kg}$ tamoxifen intraperitoneally at 4-6 weeks of age for five consecutive days using a 26 gauge $3 / 8$ " beveled needle. Posttamoxifen recovery times of 10 days or 6 weeks were incorporated prior to use of mice in experiments. Experiments using vehicle control injections were performed in a similar manner using corn oil as vehicle.

\section{Acute TMEV and TMEV-OVA Infection}

The Daniel's strain of TMEV was prepared as previously described (13). TMEV-XhoI-OVA8 (TMEV-OVA) was generated and prepared by our group as previously described (34). At 5-12 
weeks of age, mice were anesthetized with 1-2\% isoflurane and infected intracranially (i.c.) with $2 \times 10^{6} \mathrm{PFU}$ of the Daniel's strain of TMEV, or $2 \times 10^{5} \mathrm{PFU}$ of TMEV-OVA. Virus was delivered to the right hemisphere of the brain in a final volume of $10 \mu \mathrm{L}$ using an automatic $1 \mathrm{~mL}$ Hamilton syringe (Hamilton Company, Reno, NV). Mice were euthanized for flow cytometry or immunofluorescence at 0-, 5-, or 7-days post infection (dpi).

\section{PLX3397 Administration}

PLX3397 was synthesized by Plexxicon Inc. (Berkeley, CA) and formulated in AIN-76A standard chow by Research Diets Inc. (New Brunswick, NJ) at $290 \mathrm{mg} / \mathrm{kg}$. AIN-76A standard chow alone was used as respective controls. Diets were provided to mice for two weeks ad libitum.

\section{BrdU Administration}

BrdU (BD Pharmingen, Cat\#51-2420KC) was administered by intraperitoneal injection of a $100 \mathrm{uL}$ solution of $10 \mathrm{mg} / \mathrm{mL}$ at day 6 post intracranial TMEV infection according to manufacturer's instructions.

\section{Isolation of Immune Cells From Secondary Lymphoid Organs}

Spleens, cLNs, and thymi were harvested in $5 \mathrm{~mL}$ RPMI (RPMI 1640 , Gibco) and gently homogenized between the frosted glass of two glass microscope slides. Samples were washed once at $400 \mathrm{xg}$ with RPMI in $15 \mathrm{~mL}$ conical tubes. Next, $1 \mathrm{~mL}$ of ACK lysis buffer ( $8.3 \mathrm{~g}$ ammonium chloride, $1 \mathrm{~g}$ potassium bicarbonate, and $37.2 \mathrm{mg}$ EDTA) was added to the spleen samples for 1 minute to lyse erythrocytes. To quench the ACK reaction, $14 \mathrm{~mL}$ RPMI was added, and samples were washed once more prior to staining for flow cytometric analysis.

\section{Isolation of Immune Cells From Whole Brain}

Immune cells were isolated from mouse brain as previously described (35). Briefly, mice were deeply anesthetized with isoflurane and transcardially perfused with $30 \mathrm{~mL}$ of ice cold 1X PBS via intracardiac puncture. Whole brains were collected into $5 \mathrm{~mL}$ of ice cold RPMI and manually homogenized using a $7 \mathrm{~mL}$ glass Tenbroeck tissue grinder (Pyrex \#7727-07). Homogenized brain samples were then filtered through a 70 $\mu \mathrm{m}$ filter (Falcon \#352350) into a 30\% Percoll gradient (Millipore Sigma, Darmstadt, Germany - \#P4937) and centrifuged at 7840xg. The floating myelin debris layer was subsequently removed, and leukocytes were collected. Samples were washed twice with $1 \mathrm{X}$ PBS prior to staining for flow cytometric analysis.

\section{Flow Cytometry}

Cells were counted using a hemocytometer (Hausser Scientific) using trypan blue exclusion (Gibco) prior to being plated in a 96well v-bottom plate. When applicable, samples were stained with $50 \mu \mathrm{L}$ of a 1:50 dilution of $\mathrm{D}^{\mathrm{b}}: \mathrm{VP} 2_{121-130}$ APC-labeled tetramer or a 1:50 dilution of $\mathrm{K}^{\mathrm{b}}$ : $\mathrm{OVA}_{257-264}$ APC-labeled tetramer $(\mathrm{NIH}$ Tetramer Core Facility, Emory University). Tetramer staining was performed for 25 minutes in the dark at room temperature. Subsequently, samples were stained with the relevant combination of surface and intracellular antibodies in combination with Fc blocking antibody CD16/CD32 (BD Pharmingen, Cat. \#553141). BV421 anti-MHCII(IA/IE) (BioLegend, Cat. \#107632), Spark NIR 685 anti-CD45R/B220 (BioLegend, Cat. \#103268), PE-CF594 anti-CD45 (BD Pharmingen, Cat \#562420), PE anti-H-2Db (ThermoFisher, Cat. \# A15443), PerCP anti-Ly6C (BioLegend, Cat. \#128028), BB515 anti-CD11b (BD Pharmingen, Cat. \#564454), APC/ Fire750 anti-CD62L (BioLegend, Cat. \#104450), PE-Cy7 antiTCR $\beta$ (Tonbo, Cat. \#60-5961), Alexa Fluor 700 anti-H-2Kb (BioLegend, Cat. \#116521), Pacific Blue anti-CX3CR1 (BioLegend, Cat. \#149038), BV650 anti-CD44 (BD Pharmingen, Cat. \#740455), BV510 anti-CD4 (BioLegend, Cat. \#100449), BV570 anti- CD8 $\alpha$ (BioLegend, Cat. \#100740), BV605 anti-CD11c (BioLegend, Cat. \#117333), BV711 anti-Ly6G (BioLegend, Cat. \#127643), BV785 anti-F4/80 (BioLegend, Cat. \#123141) antibodies were used at 1:100 dilution to stain cells from all tissues. Zombie NIR viability dye (BioLegend, Cat. \#423105) was used at a 1:1000 dilution to stain dead cells. Samples were run on a BD LSRII flow cytometer equipped with FACSDiva software or a Cytek Aurora flow cytometer equipped with SpectroFlo software. Samples run on the LSR II were compensated with single stain controls, and samples run on the Cytek Aurora were unmixed with single stain reference controls.

\section{Immunofluorescence and Microscopy}

Mice were deeply anesthetized with isoflurane and transcardially perfused with $30 \mathrm{~mL}$ of ice cold 1X PBS followed by $30 \mathrm{~mL}$ of ice cold 4\% paraformaldehyde (PFA). For intravascular labeling experiments, mice were injected with $70 \mathrm{kDa}$ Dextran conjugated to Texas Red (Invitrogen, Cat. \#D1830) 7.5 minutes prior to anesthetization. Tissues were post-fixed overnight in $4 \%$ PFA at $4^{\circ} \mathrm{C}$, then incubated $24 \mathrm{~h}$ in $15 \%$ sucrose at $4^{\circ} \mathrm{C}$, and finally incubated $24 \mathrm{~h}$ in $30 \%$ sucrose at $4^{\circ} \mathrm{C}$ prior to embedding in Tissue-Tek OCT Compound (Sakura Finetek, Torrance, CA). Tissues were then sectioned at 20-um thickness by cryostat (Leica Biosystems, Wetzlar, Germany) onto positively charged glass slides. Slides were blocked for 1 hour in PBS containing 1\% BSA, $10 \%$ normal goat serum, and $0.1 \%$ Triton-X 100 Sigma-Aldrich) prior to incubation overnight at $4^{\circ} \mathrm{C}$ with primary antibody diluted in block buffer: Rabbit anti-Ibal (1:1000 019-19741, Wako, Osaka, Japan), Rabbit anti-NeuN (1:1000, Abcam, Cat. \#104225). Slides were then washed with 1X PBS 3 times prior to incubation with fluorochrome-conjugated secondary antibody (goat anti-rabbit Alexa Fluor 647, ThermoFisher, Cat. \#A-21245) for 1 hour at room temperature. Finally, slides were washed 5 times with $1 \mathrm{X}$ PBS prior to being mounted with VectaShield medium containing DAPI (Vector lab, Burlingame, CA).

Sections (greater than 3 sections per mouse) for Iba1+/CX3CR1+ cell density analysis or NeuN+ analysis were imaged with the Zeiss AxioObserver.Z1 structured illumination system (Carl Zeiss Microscopy GmbH, Jena, Germany) using a 40x objective. TIFF images were exported using Zen Blue software. For Iba1+ or CX3CR1+ cell morphology analysis (soma, Skeleton, and Sholl analysis), and vascular analysis, slides were imaged at room temperature using a Leica DM2500 (Wetzlar, Germany) equipped 
with a x63 oil immersion objective (confocal image: 521x521). 25micrometer $\mathrm{z}$-stacks were acquired with a step thickness of $1.01 \mathrm{um}$. Uncompressed TIFF images were exported from Leica Acquisition Suite software.

\section{Plaque Assay}

Infectious virus plaque assay was conducted using whole brain homogenates as previously described (36). Briefly, whole brains were collected from deeply anesthetized mice (isoflurane) and perfused with $30 \mathrm{~mL}$ ice cold $1 \mathrm{X}$ PBS. Brains were weighed, then sonicated until fully homogenized. Homogenate was clarified by centrifugation at $1000 \mathrm{xg}$ for 20 minutes.

L2 cells (ATCC CCL-149 ${ }^{\mathrm{TM}}$ ) were grown in DMEM w L-glut (Gibco), 10\% Heat-Inactivated Fetal Bovine Serum and 1\% penicillin-streptomycin (Sigma) and plated onto 12 -well plates at $1 \times 10^{6}$ cells/well. The assay was performed once the cells reached confluency. Confluent cells were washed once with serum-free DMEM. Next, 10-fold dilutions of tissue homogenate were prepared in serum-free DMEM and $200 \mu \mathrm{L}$ of each dilution was applied in triplicates onto cells. Plates were incubated at $37^{\circ} \mathrm{C}$ for 1 hour before $1 \mathrm{~mL}$ of a $0.8 \%$ agarose overlay was added. After 72 hours of incubation at $37^{\circ} \mathrm{C}$, cells were fixed with EAF fixative (EtOH : HOAc:formaldehyde 6:2:1) for 1 hour prior to aspiration of agarose+fixative and staining with Crystal Violet solution (1\% crystal violet in $20 \% \mathrm{EtOH})$. Plaques were counted by hand and PFU/g tissue was calculated.

\section{Bone Marrow Isolation and Set Up of Chimeras}

Femurs and tibias were isolated from donor mice. Spongey bones were cut off and bone marrow was flushed out under sterile conditions with a $21 \mathrm{G}$ needle. Cell suspensions were then lysed with ACK lysis buffer, washed twice at $400 x g$, and transferred intravenously into lethally irradiated recipient mice. Recipient mice received two doses of 450 gray irradiation four hours apart using a Shepherd's CS 137 irradiator. Donor chimerism was assessed in peripheral blood at 6 weeks post-engraftment using flow cytometry.

\section{Novel Object Recognition Testing}

Novel object recognition testing was conducted as previously described (37). In brief, mice were habituated to a $33 \mathrm{~cm}$ x $33 \mathrm{~cm}$ acrylic open field apparatus for 5 minutes per single mouse one day prior to the assay. The next day, mice were trained via exposure to two identical objects (red wooden blocks) arranged in opposite quadrants and $5 \mathrm{~cm}$ away from the walls. One mouse at a time was placed in the center of the open field with control objects and allowed to behave freely for 10 minutes. The mouse was then returned to the home cage for 1 hour prior to the novel object recognition testing session. Testing sessions consisted of a 5-minute exposure to one control object (the red wooden block) and one novel object (randomly assigned object differing in shape and texture made of Lego bricks), both placed in opposite quadrants and $5 \mathrm{~cm}$ away from the walls. All trials were conducted in a quiet, isolated procedure room under dim lighting. The open field apparatus and all objects were cleaned with $70 \%$ ethanol and dried in between each animal and each session. EthoVision XT software (Noldus Information Technology, Wageningen, the Netherlands) was used to record and count the number of investigations/sniffs of each object. The number of interrogations of the novel object as compared to the number of interrogations of the familiar object was calculated for the 5-minute test session (Discrimination Index = novel/ familiar), and the number of interrogations of each control object were compared for the 10-minute training session (familiar/familiar). A mouse with equivalent exploratory behavior and learning/recognition memory would have a discrimination index of 1 during training and greater than 1 during testing, indicating more exploration of the novel object.

\section{Magnetic Resonance Imaging}

Magnetic resonance images were acquired as previously described (27, 38). A Bruker Avance II 300-MHZ (7T) verticalbore small-animal animal system was used to conduct T2weighted scans (Bruker Biospin, Billerica, MA, USA). Mice were anesthetized under $1.5-2 \%$ isoflurane for the entirety of scanning via nose cone and respiratory rate and temperature were monitored using the SAII MRI-compatible monitoring and gating system (SA Instruments, Stony Brook, NY, USA). A respiratory gated $\mathrm{T} 2$-weighted volume acquisition rapid acquisition with refocused echoes (RARE) pulse sequence was used for scanning with the following metrics: a TR of 1,500 ms, a TE of 65 ms, a RARE factor of 16, a FOV of 4.0 by 1.92, and a matrix of 200 by 96 by 96 . Analysis and quantification of brain atrophy were performed as previously described (38). Briefly, 3dimensional volumetric analysis was conducted using Analyze 12.0 software to analyze MRI scans and generate lateral ventricle volumes (Biomedical Imaging Resource, Mayo Clinic). Semiautomated thresholding and seed growing-based algorithms were used to segment T2-weighted brain images. Object maps defining subvolumes of the brain, the two lateral ventricles, were generated and the Region of Interest Scan Tool was used to measure the volume. The investigator conducting the analysis was blinded and previously trained on test data sets.

\section{QUANTIFICATION AND STATISTICAL ANALYSIS}

\section{Processing of Flow Cytometry Data}

All samples were analyzed using FlowJo v10 (FlowJo LLC, Ashland, OR). Live, single, quality-controlled, and compensated/unmixed events covering 20 samples originating from naïve and infected B6 mice were equivalently downsampled to more than 1500 events per sample (https://www.flowjo.com/ exchange/\#/plugin/profile?id=25). We ran UMAP on the concatenated data, using 15 nearest neighbors ( $\mathrm{nn}$ ), a min_dist of 0.5, and Euclidean distance (https://arxiv.org/abs/1802. 03426). Identified populations were confirmed by manual gating.

\section{Analysis and Quantification of Immunofluorescent Images}

All image analysis was performed using Fiji software (ImageJ, U. S. National Institutes of Health, Bethesda, Maryland, USA). 
Confocal z-stacks were smoothed and compressed into a single $\mathrm{Z}$-projection Confocal images were analyzed in Z-projected images (20 slices, maximum intensity projection). Cell numbers and density quantification was completed using the Fiji (ImageJ) Analyze Particles function after uniform thresholding. Vessel-associated CX3CR1+ cells were defined using methods described by Haruwaka et al. (39). Briefly, a vertical line was drawn from the presumed center of the soma of a CX3CR1+ cell (labeled by eGFP) to the outer surface of the blood vessel (labeled by dextran). The Multiplot function in Fiji (ImageJ) was utilized to calculate the relative fluorescence intensities of GFP and Texas Red along this line, then the standard deviation of fluorescent intensity was calculated for each channel. Finally, the distance between the point where the eGFP signal decreased to zero and the Texas Red signal increased from zero was assessed. Vessel-association was defined as a distance between green and red signals as below $1 \mu \mathrm{m}$, and the percent vessel-associated of total CX3CR1+ cells per ROI was calculated. For Sholl and Skeleton analysis, each maximum intensity projection Z-stack image was uniformly thresholded. The Sholl analysis plugin of ImageJ was applied (40). The area under the curve generated by Sholl analysis per individual animal was calculated. CNS-myeloid cell soma size was measured using the segmented line tool in Fiji (ImageJ). Finally, a skeleton was created to assess CNS-myeloid cell morphology and branching using the AnalyzeSkeleton plugin (41).

\section{Statistical Analysis and Reproducibility}

Sample sizes were chosen on the basis of standard power analysis conducted on historical experimental groups, with alpha $=0.05$ and power of 0.8. Experimenters were blinded to the identity of experimental groups for non flow-cytometric experiments. GraphPad Prism 8.0.1 software (La Jolla, CA) was used to perform statistical analyses. Data are presented as mean +/$\mathrm{SD}$. All statistical tests were performed following verification of the assumptions on the distribution of data using Shapiro-Wilk normality test and D'Agostino-Pearson normality test, and nonparametric tests were used if assumptions were not met. Multiple independent groups were compared using one-way ANOVA with Tukey's multiple comparison test, and two group comparisons were made using unpaired Student's t-test or Welch's student t-test, with alpha $=0.05$ for significance. Specific tests used are detailed in figure legends. All reagents and resources employed in this study are listed in Table $\mathbf{1 .}$

\section{RESULTS}

\section{CNS-Myeloid Cells Are the Primary Immune Cell That Upregulates MHC Class I During Viral Infection of the Brain}

In order to define APCs responding to intracranial TMEV infection, we isolated cells from the brains of healthy and TMEV infected C57BL/6 mice at 7 days post infection (dpi) and used high-dimensional flow cytometry accompanied with unbiased clustering (Figure 1A). We chose $7 \mathrm{dpi}$ as it is the peak
TABLE 1 | Key Resources.

\begin{tabular}{|c|c|c|}
\hline REAGENT or RESOURCE & SOURCE & IDENTIFIER \\
\hline \multicolumn{3}{|l|}{ Antibodies } \\
\hline Fc blocking antibody CD16/CD32 & BD Pharmingen & Cat. \#553141 \\
\hline BV421 anti-MHCI(IA/IE) & BioLegend & Cat. \#107632 \\
\hline Spark NIR 685 anti-CD45R/B220 & BioLegend & Cat. \#103268 \\
\hline PE-CF594 anti-CD45 & BD Pharmingen & Cat \#562420 \\
\hline PE anti-H-2Db & ThermoFisher & Cat. \# A15443 \\
\hline PerCP anti-Ly6C & BioLegend & Cat. \#128028 \\
\hline BB515 anti-CD11b & BD Pharmingen & Cat. \#564454 \\
\hline APC/Fire750 anti-CD62L & BioLegend & Cat. \#104450 \\
\hline PE-Cy7 anti-TCR $\beta$ & Tonbo & Cat. \#60-5961 \\
\hline Alexa Fluor 700 anti-H-2Kb & BioLegend & Cat. \#116521 \\
\hline Pacific Blue anti-CX3CR1 & BioLegend & Cat. \#149038 \\
\hline BV650 anti-CD44 & BD Pharmingen & Cat. \#740455 \\
\hline BV510 anti-CD4 & BioLegend & Cat. \#100449 \\
\hline BV570 anti- CD8 $\alpha$ & BioLegend & Cat. \#100740 \\
\hline BV605 anti-CD11c & BioLegend & Cat. \#117333 \\
\hline BV711 anti-Ly6G & BioLegend & Cat. \#127643 \\
\hline BV785 anti-F4/80 & BioLegend & Cat. \#123141 \\
\hline Rabbit anti-lba1 & Wako & 019-19741 \\
\hline Rabbit anti-NeuN & Abcam & Cat. \#104225 \\
\hline goat anti-rabbit Alexa Fluor 647 & ThermoFisher & \#A-21245 \\
\hline \multicolumn{3}{|l|}{ Bacterial and virus strains } \\
\hline Daniel's strain - TMEV & $\begin{array}{l}\text { This lab, Pl: Aaron } \\
\text { Johnson }\end{array}$ & $\mathrm{N} / \mathrm{A}$ \\
\hline TMEV-Xhol-OVA8 & Pavelko et al. (34) & $\mathrm{N} / \mathrm{A}$ \\
\hline
\end{tabular}

Biological samples

Chemicals, peptides, and recombinant proteins

Tamoxifen

Sigma-Aldrich T5648

PLX3397 (CSF1Ri) Plexxicon Inc.

Bromodeoxyuridine (BrdU)

BD Pharmingen

PLX3397

Critical commercial assays

Deposited data

Experimental models: Cell lines

L2 Cells

ATCC

CCL-149 ${ }^{\mathrm{TM}}$

Experimental models: Organisms/strains

C57BL/6J

B6.PL-Thy1/CyJ

B6.129P2(Cg)-Cx3cr1tm2.1(cre/

ERT2)Litt/WganJ

B6.129P2(Cg)-Cx3cr1 ${ }^{\text {tm1Litt/J }}$

Transgenic B6.H-2DbLoxP $(\mathrm{H}-$

2Db fl/fl)

Transgenic B6.H-2KbLoxP $(\mathrm{H}-$

$2 \mathrm{~Kb} f \mathrm{fl} / \mathrm{ll})$

Jackson Laboratories

Jackson Laboratories

Jackson Laboratories

Jackson Laboratories

Tritz et al. (13)

N/A

Malo et al. (14)

$\mathrm{N} / \mathrm{A}$

Oligonucleotides

Primers for CX3CR1cre: Forward: Integrated DNA

AAG ACT CAC GTG GAC CTG Technologies

N/A

Stock No. 000664

Stock No. 000406

Stock No. 021160

Stock No. 005582

N/A

CT; Mutant, Reverse: CGG TTA

TTC AAC TTG CAC CA; WT,

Reverse: AGG ATG TTG ACT

TCC GAG TTG

Recombinant DNA

Software and algorithms
ImageJ/FIJ|

Schneider et al. (42); US National Institutes of Health

Analyze 12.0

Biomedical Imaging Resource, Mayo Clinic

FlowJo LLC

N/A

https://imagej.nih. gov/ij/

N/A

FlowJo v10 
TABLE 1 | Continued

\begin{tabular}{|c|c|c|}
\hline REAGENT or RESOURCE & SOURCE & IDENTIFIER \\
\hline UMAP & Mclnnes et al. (43) & $\begin{array}{l}\text { https://arxiv.org/ } \\
\text { abs/1802.03426 }\end{array}$ \\
\hline Sholl analysis plugin & Ferreira, TA et al. (40) & $\mathrm{N} / \mathrm{A}$ \\
\hline Analyze Skeleton Plugin & $\begin{array}{l}\text { Arganda-Carreras, I } \\
\text { et al. (41) }\end{array}$ & $\mathrm{N} / \mathrm{A}$ \\
\hline EthoVisionXT software & $\begin{array}{l}\text { Noldus Information } \\
\text { Technology }\end{array}$ & $\mathrm{N} / \mathrm{A}$ \\
\hline \multicolumn{3}{|l|}{ Other } \\
\hline $\mathrm{K}^{\mathrm{b}}$ : OVA tetramer & $\begin{array}{l}\text { NIH Tetramer Core } \\
\text { Facility (Emory) }\end{array}$ & $\mathrm{N} / \mathrm{A}$ \\
\hline$D^{\mathrm{b}}:$ VP2 tetramer & $\begin{array}{l}\text { NIH Tetramer Core } \\
\text { Facility (Emory) }\end{array}$ & $\mathrm{N} / \mathrm{A}$ \\
\hline $\begin{array}{l}70 \text { kDa Dextran conjugated to } \\
\text { Texas Red }\end{array}$ & Invitrogen & Cat. \#D1830 \\
\hline
\end{tabular}

of TMEV-specific CD8 T cell responses in C57BL/6 mice (44). Using the Uniform Manifold Approximation and Projection for Dimension Reduction (UMAP) algorithm, we mapped live $\mathrm{CD}_{4} 5^{+}$populations onto a $2 \mathrm{D}$ space and identified 7 unique clusters of $\mathrm{CD} 45^{+}$cells, whose expression of various cell surface phenotypic markers broadly identified the population (Figures 1B and S1A, B). We manually confirmed the identity of these populations based on known surface markers and assigned manual gates in subsequent experiments (Figure S1C).

Consistent with prior reports, we observed that the naive mouse brain harbors primarily CNS-resident myeloid cells (93.78\% +/- 1.29) (Figures 1B, C), which includes parenchymal microglia and perivascular macrophages. CD $45^{\text {hi }}$ B220 ${ }^{+} \mathrm{B}$ cells were the second most abundant immune cells in the naïve brain $(3.134 \%+/-0.77)$ (Figure 1D). The remaining $\mathrm{CD}^{+} 5^{+}$cells consisted of CD8 $\mathrm{T}$ cells (CD45 ${ }^{\mathrm{hi}} \mathrm{TCR}^{+} \mathrm{CD}^{+} \alpha^{+}, 0.26 \%+/-$ 0.11), CD4 $\mathrm{T}$ cells $\left(\mathrm{CD} 45^{\mathrm{hi}} \mathrm{TCR} \beta^{+} \mathrm{CD} 4^{+}, 0.34 \%+/-0.15\right)$, inflammatory monocytes $\left(\mathrm{CD} 45^{\mathrm{hi}} \mathrm{CD}_{11 \mathrm{~b}^{+}}\right.$Ly6C $^{\text {hi }} \mathrm{Ly}_{6 \mathrm{G}^{-}}$, $0.24 \%+/-0.11)$, Ly6C ${ }^{\text {low }}$ infiltrating myeloid cells $\left(\mathrm{CD} 45^{\text {hi }}\right.$ $\mathrm{CD}_{11 b^{+}}$Ly6C $^{\text {low }}$ Ly6G $\left.6.16 \%+/-0.12\right)$, and ILC/NK/other $\left(\mathrm{CD}_{4} 5^{\text {hi }} \mathrm{CD} 1 \mathrm{~b}^{-} \mathrm{TCRb}^{-} \mathrm{B} 220^{-}, 0.907+/-0.19\right)$ (Figure 1D). In comparison, at 7 days post TMEV infection, hematopoietic cells infiltrate the brain, resulting in reduced proportions of CNSmyeloid cells $\left(55.53 \%+/-9.39\right.$ of the total $\mathrm{CD} 45^{+}$population, Figure 1E). CD8 $\mathrm{T}$ cells predominated the infiltrate, making up $15.91 \%+/-3.77$ of the CD $45^{+}$cells, followed by $6.96 \%+/-1.30$ CD4 T cells, $4.361 \%+/$ - 2.18 inflammatory monocytes, $2.40 \%+/$ $0.68 \mathrm{Ly}^{6} \mathrm{C}^{\text {low }}$ infiltrating myeloid cells, $2.00 \%+/-0.36 \mathrm{~B}$ cells, and $4.68 \%+/-1.40 \mathrm{NK} / \mathrm{ILC} /$ other (Figure 1E). We did not detect neutrophils in our analyses. There were no significant differences in cell proportions or numbers when male and female mice were compared (Figure S1A).

We then assessed MHC class I expression by these populations. In the $\mathrm{C} 57 \mathrm{BL} / 6$ mouse, two $\mathrm{MHC}$ class I molecules are expressed: $\mathrm{H}-2 \mathrm{~K}^{\mathrm{b}}$ and $\mathrm{H}-2 \mathrm{D}^{\mathrm{b}}$. We found that $\mathrm{CD} 45^{\mathrm{hi}}$ populations expressed both $\mathrm{K}^{\mathrm{b}}$ and $\mathrm{D}^{\mathrm{b}}$ during the steady state, though the median fluorescence intensity (MFI) varied between populations indicating differences in expression levels (Figures 1F, G). CNS-myeloid cell expression of $\mathrm{K}^{\mathrm{b}}$ or $\mathrm{D}^{\mathrm{b}}$ was undetectable at steady state, but both class I molecules were markedly upregulated during TMEV infection. UMAP visualization colored by $\mathrm{H}-2 \mathrm{D}^{\mathrm{b}}$ expression indicates that the highest relative $\mathrm{H}-2 \mathrm{D}^{\mathrm{b}}$ expressing cells were CNS-myeloid cells and infiltrating myeloid cells at $7 \mathrm{dpi}$ (Figure 1F), while CNSmyeloid cells expressed relatively less $\mathrm{H}-2 \mathrm{~K}^{\mathrm{b}}$ compared to other CD $45^{+}$cells at 7 dpi (Figure 1G). The robust increase in MHC class I expression during TMEV infection was unique to CNSmyeloid cells, as demonstrated by fold change when all CD $45^{+}$ cell types were accounted for (Figures 1F, G). CD45 cells upregulated $\mathrm{K}^{\mathrm{b}}$ and $\mathrm{D}^{\mathrm{b}}$ but to a lesser extent than CNSmyeloid cells (Figures 1F, G). Overall, CNS-myeloid cells had the largest increase in MHC class I expression resulting from TMEV infection (Figure 1H).

In addition to upregulation of MHC class I, CNS-myeloid cells upregulated MHC class II (IA/IE) at 7 days post TMEV infection (Figure S2A). Previous studies contend that MHC class II upregulation was limited in experimental autoimmune encephalomyelitis (EAE) models (20). Nonetheless, about $45.81 \%+/-11.28$ of CNS-myeloid cells upregulated MHC class II at 7 days post TMEV infection, indicating that CNS-myeloid cells can express MHC class II (Figure S2A). Together, these results demonstrate that CNS-myeloid cells, the most abundant immune cells in the naïve and infected brain, upregulate both MHC class I and MHC class II during acute TMEV infection. The striking upregulation of MHC class I expression by CNSmyeloid cells suggests that CNS-myeloid cells have the potential to present antigen to infiltrating CD8 $\mathrm{T}$ cells during acute TMEV infection.

\section{CNS-Myeloid Cells Are Activated and Associate With Hippocampal Vasculature During Acute TMEV Infection}

Activation of CNS-myeloid cells is a common response to injury, neuroinflammation, and neurodegeneration $(45,46)$. We observed that CNS-myeloid cells markedly upregulated MHC class I during TMEV infection, leading us to wonder whether this was a facet of CNS-myeloid cell activation during infection. Accordingly, we assessed CNS-myeloid cell activation in the hippocampus at 7 days post TMEV infection, as the hippocampus has been reported to be a primary site of infection in C57BL/6 mice after intracranial inoculation (33). TMEV infection induced an increase in the density of hippocampal CNS-myeloid cells, indicating CNS-myeloid cell activation (Figures 2A, B). We noticed CNS-myeloid cell clustering around vasculature (Figure $\mathbf{2 A}$, inset), and measured increased association of CNS-myeloid cells with vasculature during TMEV infection (Figures 2C, D). Thus, CNS-myeloid cells are positioned for interactions with CD8 T cells infiltrating the hippocampus during acute TMEV infection. Additional morphologic changes in CNS-myeloid cells were measured in TMEV infected mice, including changes from a resting "ramified" morphology to a reactive "bushy" morphology (Figure 2E), increased soma size (Figure 2F), and reduced microglial process branching and complexity during infection (Figure 2G). Flow cytometric analyses permitted us to measure 
A

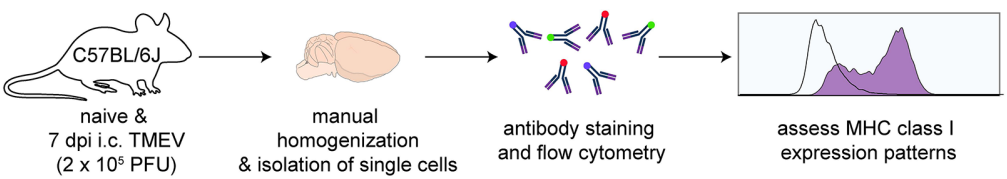

B

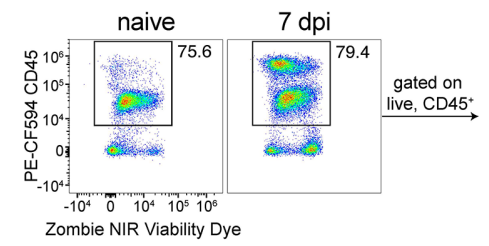

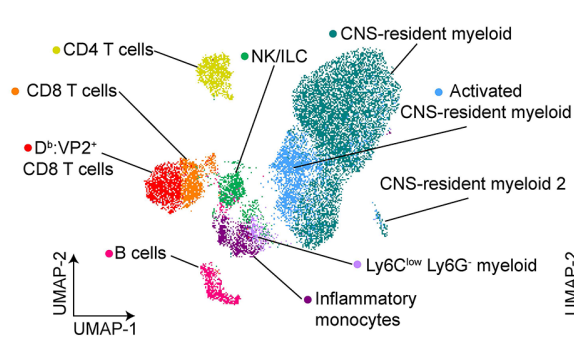

- CNS-resident myeloid

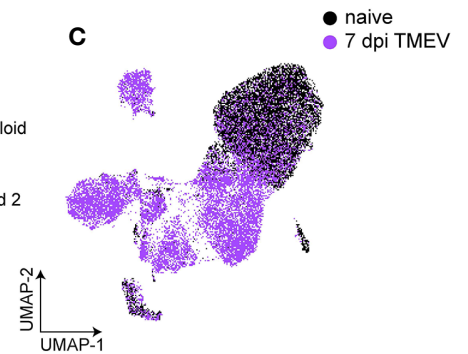

D

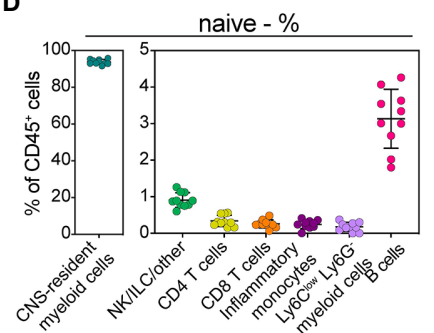

E

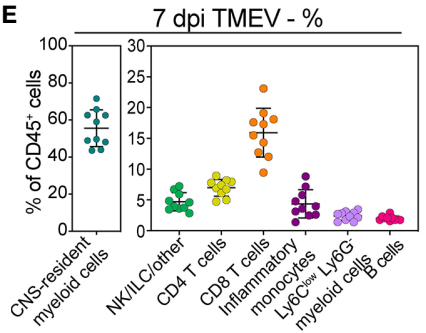

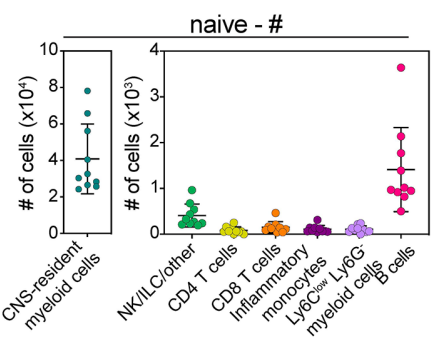

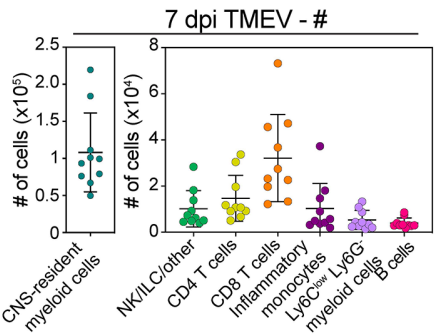

$\mathbf{F}$

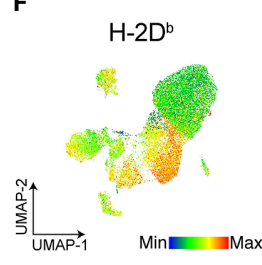

G

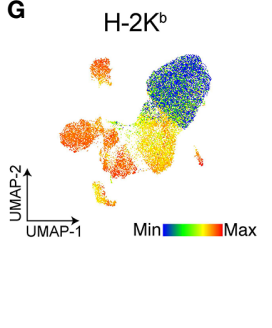

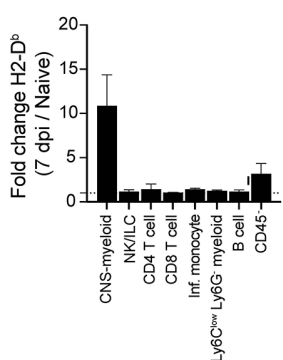

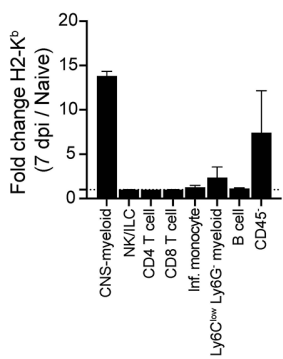

H CD45 ${ }^{\text {mid }} \mathrm{CD} 11 \mathrm{~b}^{+} \mathrm{CX} 3 \mathrm{CR} 1^{+}$(CNS-resident myeloid cells)
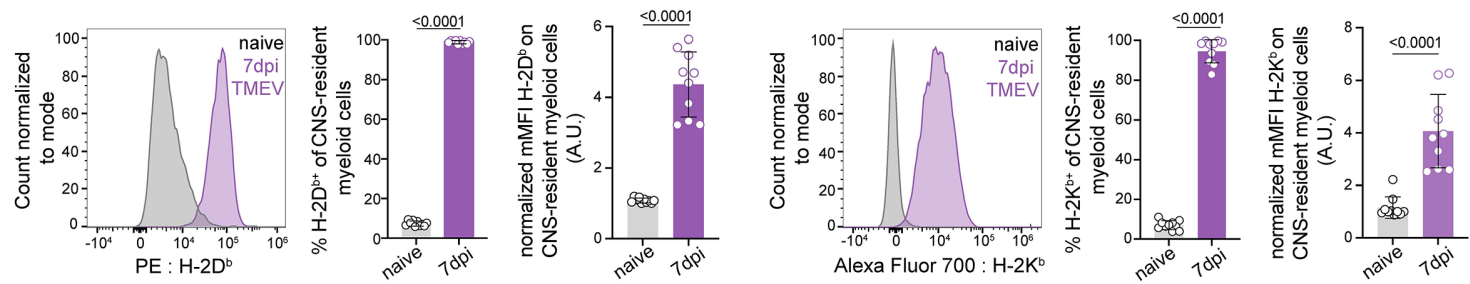

FIGURE 1 | Analysis of brain immune compartment reveals CNS-myeloid cells upregulate MHC class I in response to CNS-viral infection. (A) Experimental procedure. Brains were isolated from perfused naïve and TMEV-infected mice at 7 days post infection (dpi) $(n=10)$, dissociated using manual homogenization, and stained with fluorescently tagged antibodies for analysis of antigen presenting cells using high-dimensional flow cytometry. (B) Live CD45 ${ }^{+}$cells were downsampled and pooled for Uniform Manifold Approximation and Projection for Dimension Reduction (UMAP) analysis, identifying 7 immune cell clusters within naïve and TMEVinfected brains. (C) UMAP visualization color-coded by infection status. (D) The frequency and number of identified immune cells in the naiive brain. (E) The frequency and number of identified immune cell populations in the TMEV-infected brain at 7 dpi. (F, G) UMAP visualization of $C D 45^{+}$populations, colored by $\mathrm{H}-2 \mathrm{D}^{\mathrm{b}}$ expression (F) and $\mathrm{H}-2 \mathrm{~K}^{\mathrm{b}}$ expression (G), and fold change of $\mathrm{H}-2 \mathrm{D}^{\mathrm{b}}$ expression (F) and $\mathrm{H}-2 \mathrm{~K}^{\mathrm{b}}$ expression (G) at 7 dpi compared to naïve in $\mathrm{CD} 45^{+}$and $\mathrm{CD} 45^{-}$cell populations. (H) CNS-myeloid cells manually gated as $\mathrm{CD} 45^{\text {mid }} \mathrm{CD} 11 \mathrm{~b}^{+} \mathrm{CX} 3 \mathrm{CR} 1^{+}$were analyzed for $\mathrm{H}-2 \mathrm{D}^{\mathrm{b}}$ and $\mathrm{H}-2 \mathrm{~K}^{\mathrm{b}}$ expression using flow cytometry. Representative histograms, frequency of $\mathrm{H}-2 \mathrm{D}^{\mathrm{b}}$ and $\mathrm{H}-2 \mathrm{~K}^{\mathrm{b}}$ positive cells of the population, and normalized median fluorescence intensity (MFI) of $\mathrm{H}-2 \mathrm{D}^{\mathrm{b}}$ and $\mathrm{H}-2 \mathrm{~K}^{\mathrm{b}}$ on $\mathrm{CNS}-\mathrm{resident}$ myeloid cells. Data are representative of $\geq 3$ independent experiments and presented as mean +/- SD, 2-tailed unpaired Student's $t$ test with ns $p \geq 0.05$. dpi, days post infection. 
additional activation metrics in CNS-myeloid cells during TMEV infection. Infection increased the frequency of CX3CR $1^{\text {mid }}$ sidescatter (SSC) ${ }^{\text {low }}$ CNS-myeloid cells that were absent under steady state conditions (Figures S2B-D). SSC changes were consistent with CNS-myeloid cell morphological alterations observed in the hippocampus (Figure 2), and reduced CX3CR1 expression is related to the activated "damage associated microglia" (DAM) phenotype seen in neurodegenerative diseases (47). The frequency of $\mathrm{K}^{\mathrm{b}}, \mathrm{D}^{\mathrm{b}}$, and MHC class II expressing cells was similar between CNS-myeloid cell stratifications, though differences in MFI suggest differential levels of surface protein expression indicating contrasting activation levels between CNSmyeloid cells during TMEV infection (Figure S2E). Together, our data indicate that TMEV infection induces activation of CNS-myeloid cells that includes association with hippocampal vasculature and upregulation of MHC molecules.

\section{CSF1R Inhibition Alters Peripheral Myeloid Cell Populations and CD8 T Cell Priming}

To assess whether CNS-myeloid cells were critical APCs for CD8

T cell infiltration of the CNS, we sought to deplete CNS-myeloid cells prior to TMEV infection. Colony stimulating factor 1 receptor (CSF1R) signaling is essential for the development and survival of myeloid cells, and CSF1R inhibitors have been utilized to deplete murine microglia in experimental settings (48). We depleted CNS-myeloid cells by providing mice with the CSF1 inhibitor PLX3397 or control chow for 2 weeks. We then infected these mice with TMEV upon the start of week 2 (Figure S3A). PLX3397 treated mice were protected from acute weight loss as a result of TMEV infection (Figure S3B) but began to succumb to infection at 5 dpi. PLX3397 depleted CNS-myeloid cells as previously reported (Figure S3C). However, we found that PLX3397 treatment altered the total number of cells isolated from the spleen (Extended Data Figure S3D) and the proportion and number of CD11c+ cells and MHC II+ cells, implying peripheral $\mathrm{T}$ cell priming by dendritic cells would be impaired (Figure S3D). Indeed, virus-specific CD8 T cells primed in the spleen were reduced upon PLX3397 treatment (Figure S3D). Taken together, we determined that PLX3397 was not specific enough for our experimental question due to off-target effects on peripheral immunity in addition to CNS-myeloid cell ablation.

\section{Development of a CNS-Myeloid Cell MHC Class I Deletion Model}

Our approach using CSF1R inhibition to reduce CNS-myeloid cells unintentionally disrupted peripheral immunity. Therefore, we developed a more CNS-specific approach to dissect the role of CNS-myeloid cell antigen presentation using conditional ablation of $\mathrm{H}-2 \mathrm{~K}^{\mathrm{b}}$ or $\mathrm{H}-2 \mathrm{D}^{\mathrm{b}}$ expression. CX3CR $1^{\text {creER }}$ mice on a $\mathrm{MHC}$ class I deficient background were crossed to either $\mathrm{H}-2 \mathrm{~K}^{\mathrm{b}}$ fl/fl or $\mathrm{H}$ $2 \mathrm{D}^{\mathrm{b}} \mathrm{fl} / \mathrm{fl}$ transgenic mice that were otherwise MHC class I deficient $(13,14)$. This resulted in two strains of mice carrying the CX3CR $1^{\text {creER }}$ transgene, with either a floxed $\mathrm{H}-2 \mathrm{~K}^{\mathrm{b}}$ gene $\left(\mathrm{CX} 3 \mathrm{CR} 1^{\text {cre }} / \mathrm{K}^{\mathrm{b}}\right)$ or $\mathrm{H}-2 \mathrm{D}^{\mathrm{b}}$ gene $\left(\mathrm{CX} 3 \mathrm{CR} 1^{\mathrm{cre}} / \mathrm{D}^{\mathrm{b}}\right)$ but no other MHC class I molecules. We specifically deleted $\mathrm{H}-2 \mathrm{~K}^{\mathrm{b}}$ or $\mathrm{H}-2 \mathrm{D}^{\mathrm{b}}$ in CNS-myeloid cells by taking advantage of the long-lived, self-renewing nature of these cells in comparison to peripheral CX3CR1-expressing cells. To this end, we allowed 6-weeks to pass after tamoxifen treatment while peripheral CX3CR1-expressing cells were restored by $\mathrm{H}-2 \mathrm{~K}^{\mathrm{b}}$ or $\mathrm{H}-2 \mathrm{D}^{\mathrm{b}}$ sufficient hematopoietic precursors, and CNS-myeloid cells remained $\mathrm{H}-2 \mathrm{~K}^{\mathrm{b}}$ or $\mathrm{H}-2 \mathrm{D}^{\mathrm{b}}$ deficient. We then used flow cytometry to assess MHC class I deletion efficiency (Figures 3A, B).

The $\mathrm{CX} 3 \mathrm{CR} 1^{\text {cre }} / \mathrm{K}^{\mathrm{b}}$ system led to the robust deletion of $\mathrm{H}-2 \mathrm{~K}^{\mathrm{b}}$ in CNS-myeloid cells at baseline and during infection with TMEV expressing the model antigen ovalbumin $\left(\mathrm{OVA}_{257-264}\right)$, which is presented in the $\mathrm{K}^{\mathrm{b}}$ MHC class I molecule (Figures 3B, D) (34). High YFP expression indicated that the majority of CNS-myeloid cells were targeted by this transgenic creER approach during naïve and infected conditions (Figure 3B). Expression of $\mathrm{H}-2 \mathrm{~K}^{\mathrm{b}}$ was efficiently restored on peripheral immune cells through hematopoiesis, as there were no differences in the frequency of $\mathrm{H}-2 \mathrm{~K}^{\mathrm{b}+} \mathrm{CD} 45^{+}$cells in the spleens of $\mathrm{cre}^{+}$mice compared to cre controls (Figure 3C). CX3CR $1^{\text {cre }} / \mathrm{D}^{\mathrm{b}}$ mice were similarly evaluated (Figures 3E-H). CNS-myeloid cells from CX3CR $1^{\text {cre} /}$ $\mathrm{D}^{\mathrm{b}}$ mice expressed significantly less $\mathrm{H}-2 \mathrm{D}^{\mathrm{b}}$ than $\mathrm{cre}^{-}$animals during naive conditions and during infection with TMEV (Figures 3F, H). We observed appropriate surface expression of $\mathrm{H}-2 \mathrm{D}^{\mathrm{b}}$ in splenic immune cells (Figure 3G). These results demonstrate that $\mathrm{CX} 3 \mathrm{CR} 1^{\mathrm{cre}} / \mathrm{K}^{\mathrm{b}}$ mice and $\mathrm{CX} 3 \mathrm{CR} 1^{\mathrm{cre}} / \mathrm{D}^{\mathrm{b}}$ have sufficient deletion of $\mathrm{K}^{\mathrm{b}}$ or $\mathrm{D}^{\mathrm{b}}$ expression by CNS-myeloid cells to allow assessment of antigen presentation by this cell type.

It has been reported that $\mathrm{cre}^{\text {ERT2 }}$ lines such as the CX3CR $1^{\text {creER }}$ used in this study have the potential to exhibit spontaneous, tamoxifen-independent excision of LoxP sites (49), so we assessed the extent to which this occurred in our conditional knockout mice. We determined that $\mathrm{CX} 3 \mathrm{CR} 1^{\mathrm{cre}} / \mathrm{D}^{\mathrm{b}}$ mice treated with vehicle injections exhibited $\mathrm{D}^{\mathrm{b}}$ expression comparable to cre ${ }^{-}$controls (Figures S4A-C). Accordingly, $\mathrm{cre}^{-}$littermate controls were appropriate for the remainder of our studies. Altogether, we concluded that $\mathrm{CX} 3 \mathrm{CR} 1^{\mathrm{cre}} / \mathrm{K}^{\mathrm{b}}$ and $\mathrm{CX} 3 \mathrm{CR} 1^{\mathrm{cre}} / \mathrm{D}^{\mathrm{b}}$ mice are robust systems to specifically delete CNS-myeloid cell $\mathrm{H}-2 \mathrm{~K}^{\mathrm{b}}$ or $\mathrm{H}-2 \mathrm{D}^{\mathrm{b}}$ during neuroinflammation, providing a valuable tool for studying CNS-myeloid cell antigen presentation without unintended consequences on peripheral immunity.

\section{CX3CR1-Dependent H-2K ${ }^{b}$ or H-2D ${ }^{b}$ Deletion Does Not Impact CNS-Myeloid Cell Homeostasis or T Cell Development}

We next sought to investigate if there were any cell-intrinsic consequences of loss of MHC class I on CNS-myeloid cells. We determined that the numbers of CNS-myeloid cells isolated from the brains of $\mathrm{CX} 3 \mathrm{CR} 1^{\mathrm{cre}} / \mathrm{K}^{\mathrm{b}}$ and $\mathrm{CX} 3 \mathrm{CR} 1^{\mathrm{cre}} / \mathrm{D}^{\mathrm{b}}$ animals were comparable to cre ${ }^{-}$controls at baseline and during infection (Figures S5A-D). These data indicate that a loss of MHC class I expression on CNS-myeloid cells does not impact the survival of CNS-myeloid cells in the naïve or inflamed CNS. We then assessed whether loss of MHC class I had an impact on CNSmyeloid cell activation by performing Ibal immunostaining in naïve- and TMEV-infected CX3CR $1^{\text {cre }} / \mathrm{D}^{\mathrm{b}}$ hippocampi. We determined that CNS-myeloid cell activation in response to 
A
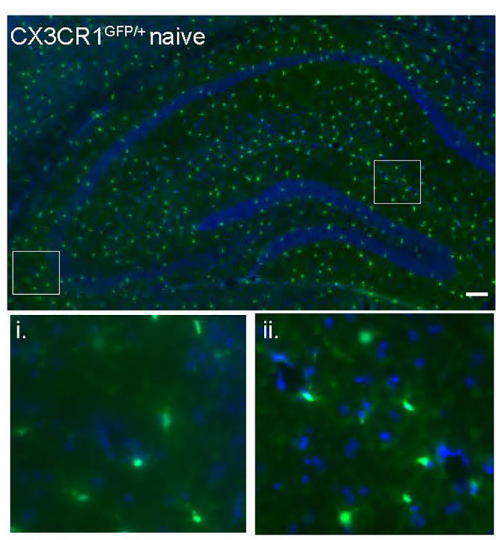

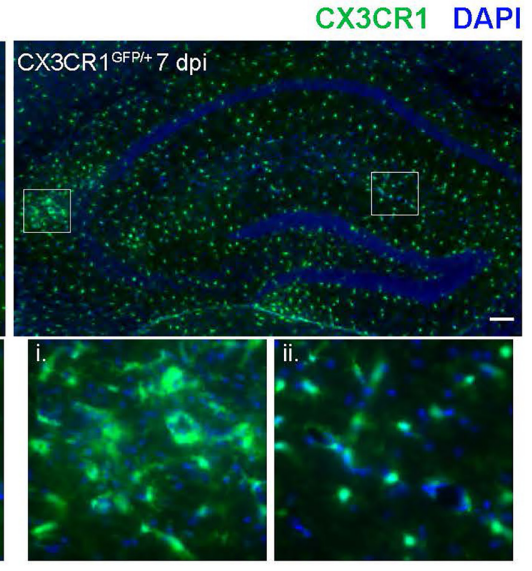

B

C
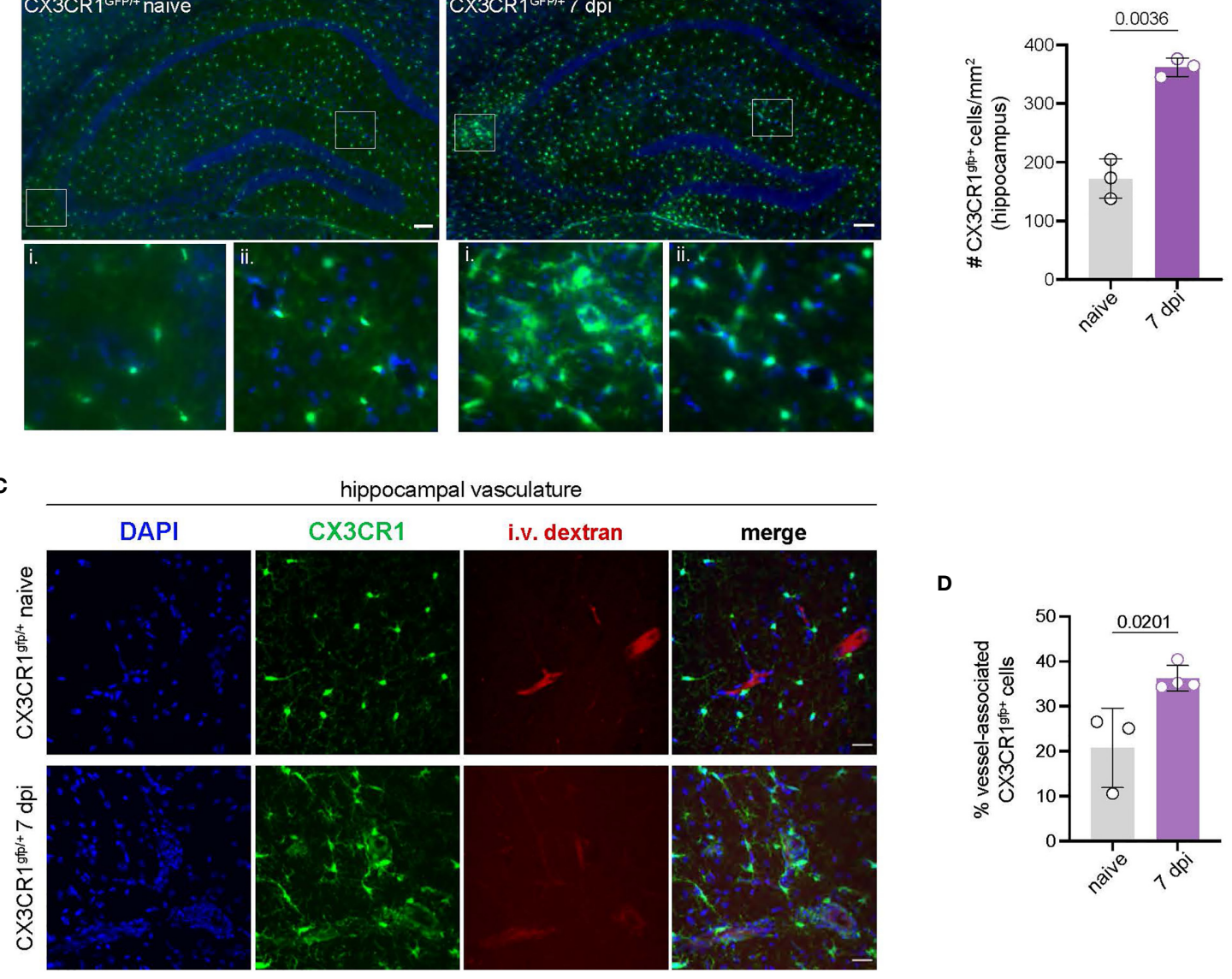

D

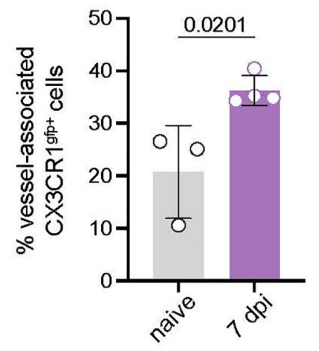

E

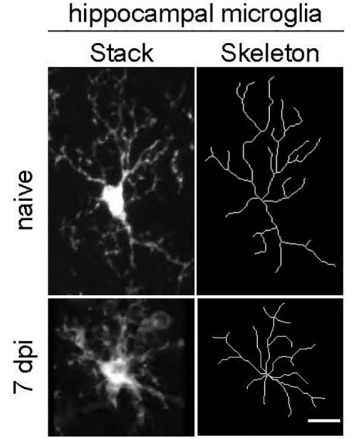

$\mathbf{F}$

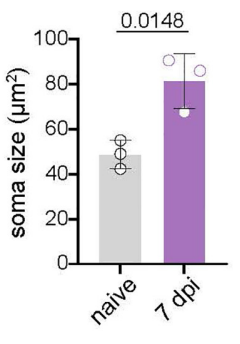

G
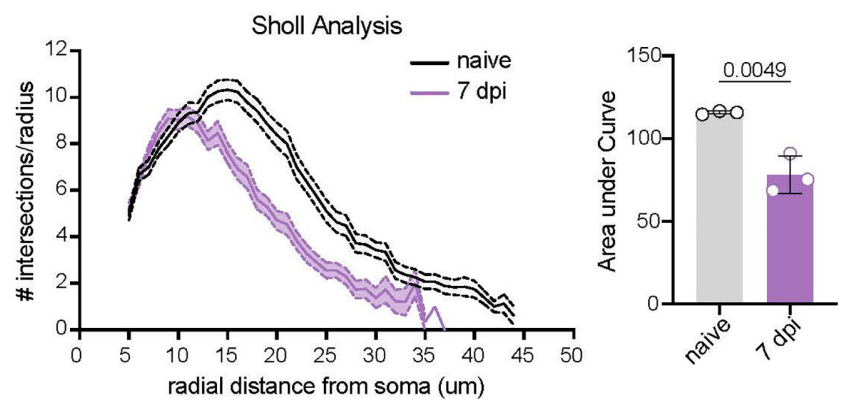

FIGURE 2 | TMEV infection induces CNS-myeloid cell activation and vessel association in the hippocampus. (A) CX3CR1 ${ }^{+}$CNS-myeloid cells (green) in representative hippocampal images from uninfected and TMEV infected (7 dpi) CX3CR $1^{\text {gfp/+ }}$ mice. Zoomed insets demonstrate areas in which $\mathrm{CX} 3 \mathrm{CR} 1^{+}$cells cluster around vasculature. $n=3$ mice (3 sections/mouse). Scale bars: $100 \mu \mathrm{m}$. (B) Density of hippocampal CX3CR1 ${ }^{+}$cells in naïve and TMEV infected mice. (C) Representative images of DAPI (nuclei, blue), CX3CR1 (CNS-myeloid, green), and intravascularly injected dextran (vasculature, red) in the hippocampus of naïve and TMEV-infected mice. $n=3$ mice (6 sections/mouse). Scale bars: $25 \mu \mathrm{m}$. (D) Quantification of the proportion of CX3CR $1^{+}$cells in contact with hippocampal vasculature in naïve and infected conditions. (E) Representative images of hippocampal microglial morphology (confocal and transformed skeletal) in uninfected and TMEV infected mice (7 dpi). $n=3$ mice (3 sections/mouse). Scale bars: $10 \mu \mathrm{m}$. (F) Quantification of hippocampal microglia soma size at 7 dpi TMEV compared to naïve. (G) Sholl analysis of microglia at 7 days post TMEV infection or during steady state. (25 microglia/section, 2 sections/mouse). Area under the curve of the Sholl analysis is used to demonstrate quantification of microglial branching during infection. Data are representative of $\geq 2$ independent experiments and presented as mean $+/-\mathrm{SD}, 2$-tailed unpaired Student's $t$ test with $n s p \geq 0.05$. 
A

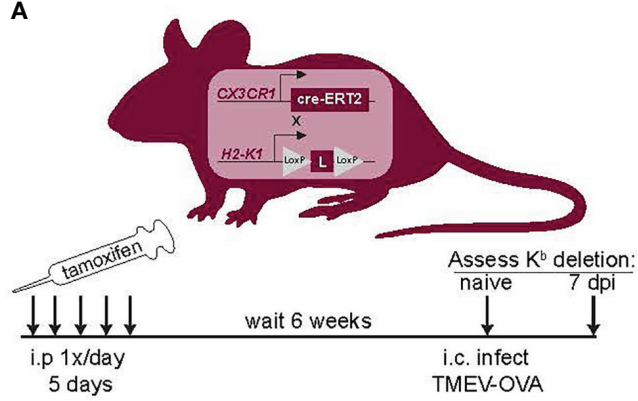

C
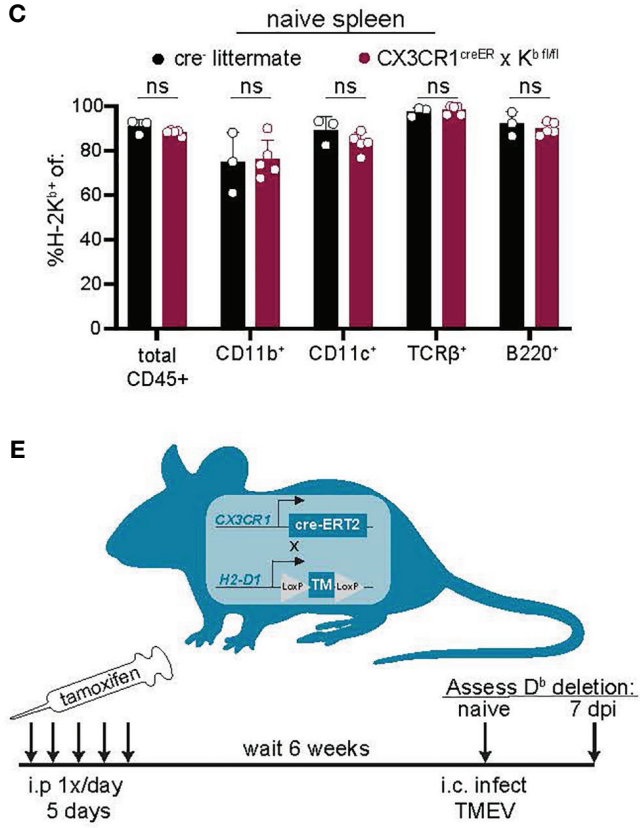

G

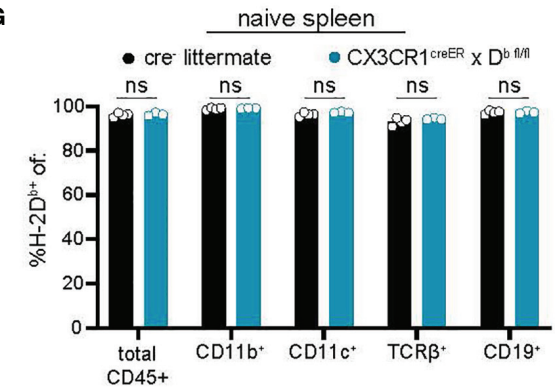

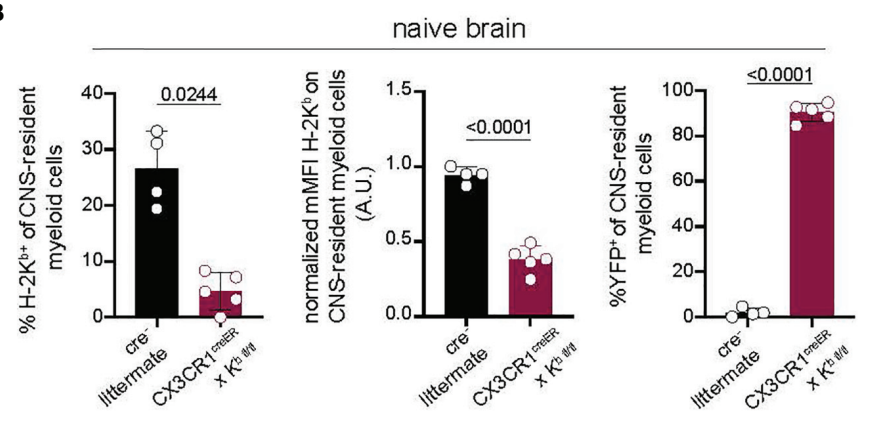

D

7 dpi TMEV-OVA

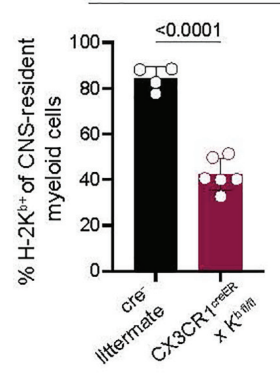

$\mathbf{F}$

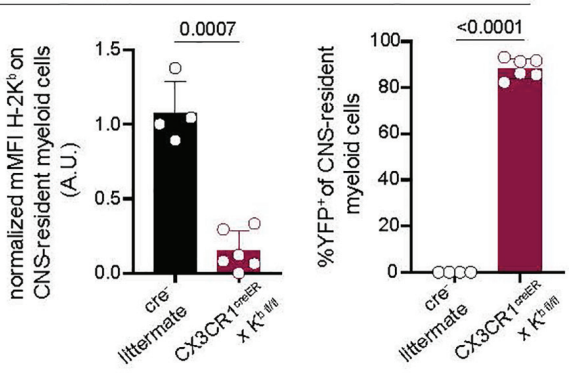

naive brain

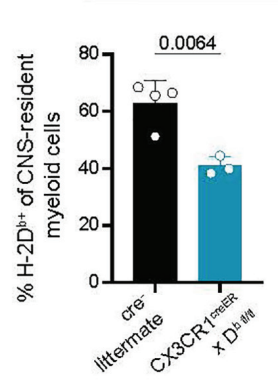

H
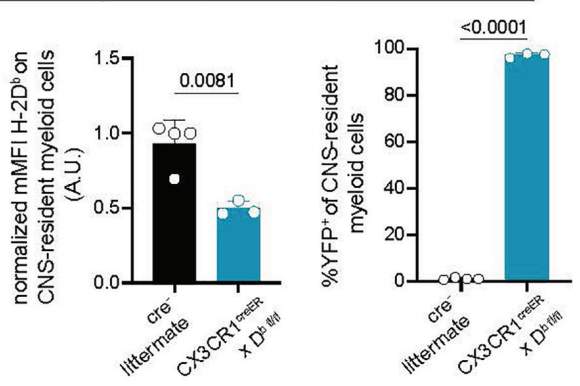

7 dpi TMEV

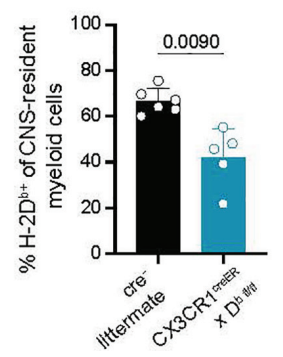

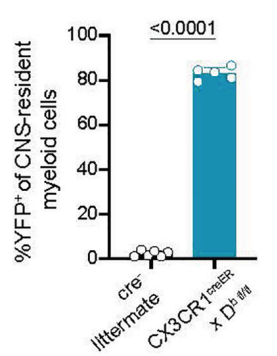

FIGURE 3 | Development of a model to conditionally delete MHC class I in CNS-myeloid cells. (A, E) MHC class I deficient CX3CR ${ }^{\text {creER }}$ mice were crossed to transgenic $\mathrm{H}-2 \mathrm{~Kb}^{\mathrm{fl} / \mathrm{fl}}$ mice (14) (A) or $\mathrm{H}-2 \mathrm{Db}{ }^{\mathrm{fl} / \mathrm{fl}}$ mice (13) (E). Tamoxifen was used to induce MHC class I deletion. After 6 weeks, $\mathrm{K}^{\mathrm{b}} / \mathrm{D}^{\mathrm{b}}$ deletion was assessed using flow cytometry. (A-D) $\mathrm{H}-2 \mathrm{~K}^{\mathrm{b}}$ expression by CNS-myeloid cells was quantified by measuring percent positive and normalized median fluorescence intensity (MFI) in naïve $\mathrm{CX} 3 \mathrm{CR} 1^{\text {cre }} / \mathrm{K}^{\mathrm{b}}$ mice and cre controls. YFP expression was measured to assess penetrance of $\mathrm{CX} 3 \mathrm{CR} 1^{\text {creER }}$ transgene. (C) $\mathrm{H}-2 \mathrm{~K}^{\mathrm{b}}$ expression was assessed in spleens of $\mathrm{CX} 3 \mathrm{CR}^{\mathrm{cre}} / \mathrm{K}^{\mathrm{b}}$ mice and cre controls. (D) $\mathrm{H}-2 \mathrm{~K}^{\mathrm{b}}$ expression by CNS-myeloid cells was quantified at 7 days post infection with TMEV expressing $\mathrm{OVA}_{257-264}$. $\mathbf{F}$ ) H-2D expression by CNS-myeloid cells was quantified by measuring percent positive and normalized median fluorescence intensity (MFI) in naiive $\mathrm{CX} 3 \mathrm{CR}_{1} 1^{\text {rre }} / \mathrm{D}^{\mathrm{b}}$ mice and cre controls. YFP expression was measured to assess penetrance of $\mathrm{CX} 3 \mathrm{CR}^{-} 1^{\text {creER }}$ transgene. (G) $\mathrm{H}-2 \mathrm{D}^{\mathrm{b}}$ expression was assessed in spleens of $\mathrm{CX} 3 \mathrm{CR} 1^{\text {cre }} / \mathrm{D}^{\mathrm{b}}$ mice and cre controls. $(\mathrm{H}) \mathrm{H}-2 \mathrm{D}^{\mathrm{b}}$ expression by CNS-myeloid cells was quantified at 7 days post infection with TMEV. For all experiments, CNS-myeloid cells are live, single cells, expressing $C D 45^{\text {mid }} \mathrm{CD} 11 \mathrm{~b}^{+} \mathrm{CX} 3 \mathrm{CR} 1^{+}$. Data are shown as individual mice with mean from one independent experiment ( $n=3-6)$ of $\geq 3$ experimental replicates. Error bars represent standard deviation. Two tailed Welch's $t$ test was used to assess statistical significance with ns $p \geq 0.05$. 
TMEV infection was not impacted by CNS-myeloid cell loss of H-2D ${ }^{b}$ expression (Figures S5E-G).

Following our analysis of the cell-intrinsic impact of $\mathrm{MHC}$ class I deletion, we sought to determine if conditional deletion of MHC class I on CX3CR1-expressing cells impacted $\mathrm{T}$ cell development. Using flow cytometry, we determined that thymocyte populations were unaffected by loss of $\mathrm{K}^{\mathrm{b}}$ or $\mathrm{D}^{\mathrm{b}}$ by CX3CR1-expressing cells (Figures S6A-C, E-G). Further, splenic CD4 and CD8 T cell frequencies were similar in CX3CR $1^{\text {cre }} / \mathrm{K}^{\mathrm{b}}$ and $\mathrm{CX} 3 \mathrm{CR} 1^{\mathrm{cre}} / \mathrm{D}^{\mathrm{b}}$ mice compared to controls (Figures S6D, H). Together, these data indicate that loss of MHC class I molecules on CX3CR1-expressing cells does not impact CNS-myeloid cell survival and activation, nor $\mathrm{T}$ cell development, providing a precise tool to dissect CNS-myeloid cell antigen presentation.

\section{H-2K ${ }^{b}$ Expression by CNS-Myeloid Cells Is Dispensable for CD8 T Cell Responses to a Model Antigen}

After confirming that $\mathrm{CX} 3 \mathrm{CR} 1^{\text {cre }} / \mathrm{K}^{\mathrm{b}}$ animals served as a specific model of $\mathrm{K}^{\mathrm{b}}$ deletion from CNS-myeloid cells, we sought to test whether CNS-myeloid cell $\mathrm{H}-2 \mathrm{~K}^{\mathrm{b}}$ is required for brain infiltration of CD8 $\mathrm{T}$ cells. Infection of $\mathrm{C} 57 \mathrm{BL} / 6$ mice by TMEV engineered to express the model antigen $\mathrm{OVA}_{257-264}$ (TMEV-OVA) generates CD8 $\mathrm{T}$ cell responses against viral antigens and OVA (34). We intracranially infected CX3CR $1^{\text {cre }}$ / $\mathrm{K}^{\mathrm{b}}$ animals and controls with TMEV-OVA (consistent with the experimental design detailed in Figure 3A) and assessed CD8 T cell responses in the spleen, cervical lymph node (cLN), and brains of these mice. The cLN is the putative site of $\mathrm{T}$ cell priming against CNS-drained antigens $(12,13)$, and the spleen reflects systemic CD8 $\mathrm{T}$ cell responses against virus. The frequencies of CD8 $\mathrm{T}$ cells and OVA-specific CD8 $\mathrm{T}$ cells in the spleens and cLNs of CX $3 C R 1^{\mathrm{cre}} / \mathrm{K}^{\mathrm{b}}$ and $\mathrm{cre}^{-}$controls were comparable (Figures 4A, B, D). Further, the frequencies of naïve (CD44-CD62L+), effector (CD44+CD62L-), and central memory $(\mathrm{CD} 44+\mathrm{CD} 62 \mathrm{~L}+) \mathrm{CD} 8 \mathrm{~T}$ cells in the spleens of CX3CR $1^{\text {cre }} / \mathrm{K}^{\mathrm{b}}$ mice did not differ from cre controls (Figure 4C). These data indicate that $\mathrm{T}$ cell priming occurs normally in $\mathrm{CX} 3 \mathrm{CR} 1^{\mathrm{cre}} / \mathrm{K}^{\mathrm{b}}$ mice, which was expected, given $\mathrm{K}^{\mathrm{b}}$ expression in the periphery was unaltered. We next sought to determine the extent of immune infiltration into the TMEV-OVA infected brain when CNS-myeloid cell $\mathrm{K}^{\mathrm{b}}$ expression was disrupted. We found no differences in CD8 T cell (Figures 4E, F), OVA-specific CD8 T cell (Figures 4G, H), CD4 T cell (Figure 4I), or inflammatory monocyte (Figure 4J) infiltration of the brain, indicating $\mathrm{H}-2 \mathrm{~K}^{\mathrm{b}}$ MHC class I expression by CNS-myeloid cells is dispensable for neuroinflammation during TMEV-OVA infection of the brain.

\section{H-2D ${ }^{b}$ Expression by CNS-Myeloid Cells Is Pivotal for Neuroinflammatory Responses to TMEV}

Because we observed that CNS-myeloid cell expression of $K^{b}$ did not impact immune infiltration of the brain during infection with TMEV-OVA (Figure 4), we next sought to investigate CNSmyeloid cell antigen presentation via the $\mathrm{D}^{\mathrm{b}}$ molecule. $\mathrm{H}-2 \mathrm{D}^{\mathrm{b}}$, but not $\mathrm{H}-2 \mathrm{~K}^{\mathrm{b}}$, has been mapped to resistance from chronic
TMEV infection (50-52). This is attributed to viral clearance by CD8 $\mathrm{T}$ cell responses against the immunodominant viral VP2 $2_{121-130}$ peptide antigen presented in context of the $\mathrm{D}^{\mathrm{b}}$ class I molecule (30). Therefore, we asked whether CNS-myeloid cell $\mathrm{H}-2 \mathrm{D}^{\mathrm{b}}$ expression is required for brain infiltration of $\mathrm{D}^{\mathrm{b}}$ : $\mathrm{VP} 2_{121-}$ ${ }_{130}$ epitope specific CD8 $\mathrm{T}$ cells during acute TMEV infection. We intracranially infected $\mathrm{CX} 3 \mathrm{CR} 1^{\mathrm{cre}} / \mathrm{D}^{\mathrm{b}}$ animals and controls with TMEV (same experimental paradigm as Figure 3E) and assessed CD8 T cell responses in the spleen, CLN, and brains of these mice. The frequencies of CD8 T cells, and $D^{\mathrm{b}}: \mathrm{VP} 2$ epitope specific CD8 T cells, in the spleens and cLNs of CX3CR1 $1^{\text {cre }} / \mathrm{D}^{\mathrm{b}}$ and control mice were comparable demonstrating that $\mathrm{T}$ cell priming is unaltered in $\mathrm{CX} 3 \mathrm{CR} 1^{\text {cre }} / \mathrm{D}^{\mathrm{b}}$ mice (Figures $5 \mathrm{~A}, \mathbf{B}, \mathbf{D}$ ). The frequencies of naïve (CD44-CD62L+), effector (CD44+CD62L-), and central memory (CD44+CD62L+) CD8 $\mathrm{T}$ cells in the spleens of $\mathrm{CX} 3 \mathrm{CR} 1^{\mathrm{cre}} / \mathrm{D}^{\mathrm{b}}$ and control mice also did not differ between genotypes (Figure 5C). These data indicate that $\mathrm{CD} 8 \mathrm{~T}$ cell priming occurs normally in $\mathrm{CX} 3 \mathrm{CR} 1^{\text {cre }} / \mathrm{D}^{\mathrm{b}}$ mice, which is consistent with the observation that peripheral $\mathrm{D}^{\mathrm{b}}$ expression was equivalent (Figure 3G).

In contrast to the equivalent peripheral $\mathrm{T}$ cell responses, we recovered reduced brain infiltrating cells in $\mathrm{CX} 3 \mathrm{CR} 1^{\mathrm{cre}} / \mathrm{D}^{\mathrm{b}}$ mice at 7 dpi with TMEV suggesting that immune infiltration of the brain was affected (Figure 5). $\mathrm{CX} 3 \mathrm{CR} 1^{\mathrm{cre}} / \mathrm{D}^{\mathrm{b}}$ mice had a diminished number of total infiltrating CD8 $\mathrm{T}$ cells in the brain, as well as reduced virus specific $\left(D^{\mathrm{b}}: \mathrm{VP} 2_{121-130}\right.$ epitope specific) CD8 $\mathrm{T}$ cells infiltrating the brain (Figures $\mathbf{5 E}-\mathbf{H}$ ). We also noted a reduction in the frequency of inflammatory monocytes in the brains of $\mathrm{CX} 3 \mathrm{CR} 1^{\text {cre }} / \mathrm{D}^{\mathrm{b}}$ animals as compared to controls (Figure 5J). There were no other differences in immune infiltrates observed in $C X 3 C R 1^{\text {cre }} / D^{b}$ animals, harboring comparable $\mathrm{CD} 4 \mathrm{~T}$ cells responses (Figure 5I), indicating the reduced immune infiltration of the brain was attributable to CNS-myeloid cell $\mathrm{D}^{\mathrm{b}}$ loss.

To determine whether the reduced number of infiltrating $\mathrm{T}$ cells in $\mathrm{CX} 3 \mathrm{CR} 1^{\text {cre }} / \mathrm{D}^{\mathrm{b}}$ mice was due to decreased $\mathrm{T}$ cell proliferation, infected $\mathrm{CX} 3 \mathrm{CR} 1^{\mathrm{cre}} / \mathrm{D}^{\mathrm{b}}$ and $\mathrm{cre}^{-}$animals were given bromodeoxyuridine (BrdU) intraperitoneally at day 6 post infection and assessed at day 7 post infection. BrdU incorporation in CD8 $\mathrm{T}$ cells revealed no changes in $\mathrm{T}$ cell proliferation in $\mathrm{CX} 3 \mathrm{CR}^{\mathrm{cre}} / \mathrm{D}^{\mathrm{b}}$ mice, indicating that the reduced $\mathrm{CD} 8 \mathrm{~T}$ cell response in the brain was not due to proliferation defects (Figure 5K). Given similar cellular proliferation, we asked whether CD8 T cells infiltrating the brain experienced increased cell death, but uncovered no differences in $\mathrm{T}$ cell viability in $\mathrm{CX} 3 \mathrm{CR} 1^{\text {cre }} / \mathrm{D}^{\mathrm{b}}$ mice compared to controls (Figure 5L). Thus, CNS-myeloid cell antigen presentation has a critical role for CD8 $T$ cell and inflammatory monocyte infiltration when these cells are presenting the immunodominant antigen during TMEV infection, independent of $\mathrm{T}$ cell proliferation or viability.

\section{CNS-Myeloid Cell Antigen Presentation Impacts TMEV Specific CD8 T Cell Responses at the Point of Brain Infiltration}

Our approach targeting CX3CR1-expressing cells to conditionally delete $\mathrm{H}-2 \mathrm{D}^{\mathrm{b}}$ is designed to impact only long-lived CNS-myeloid 
A

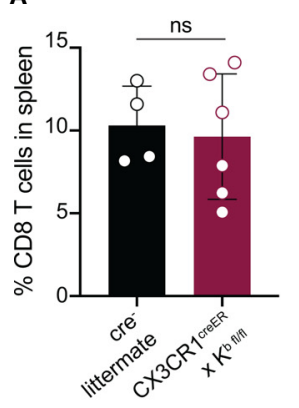

E cre-littermate

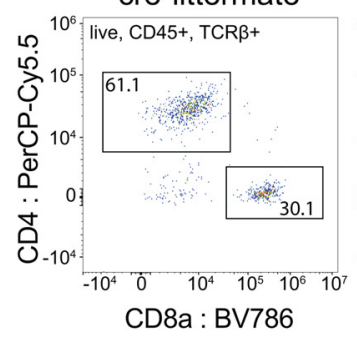

G

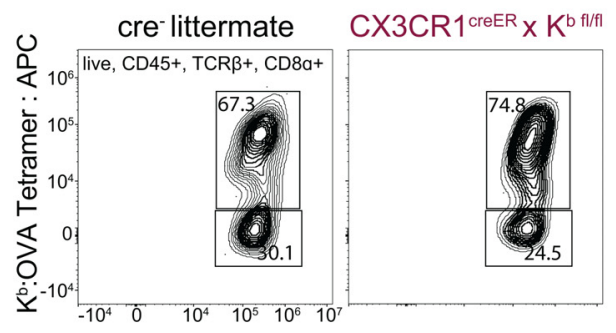

CD8a : BV786

I

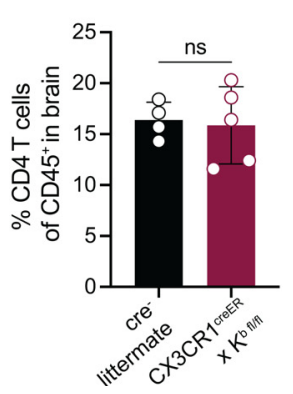

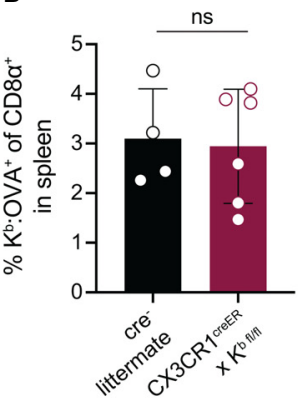

CX3CR1 ${ }^{\text {creER }} \times \mathrm{K}^{\mathrm{b} f / f 1}$

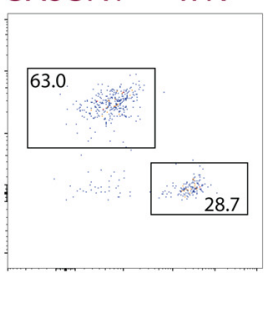

28.7
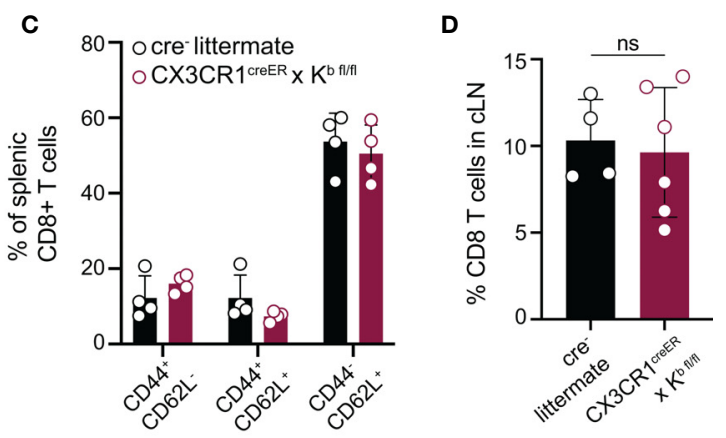

F
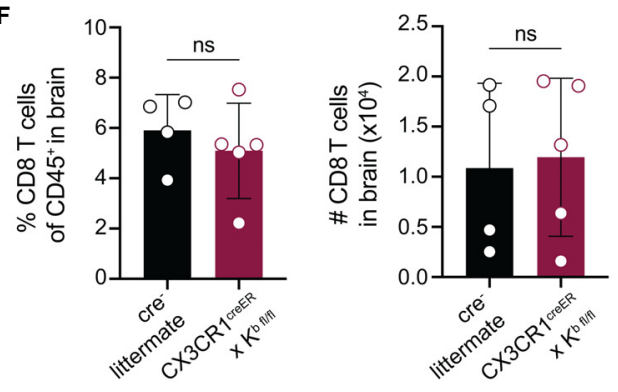

H
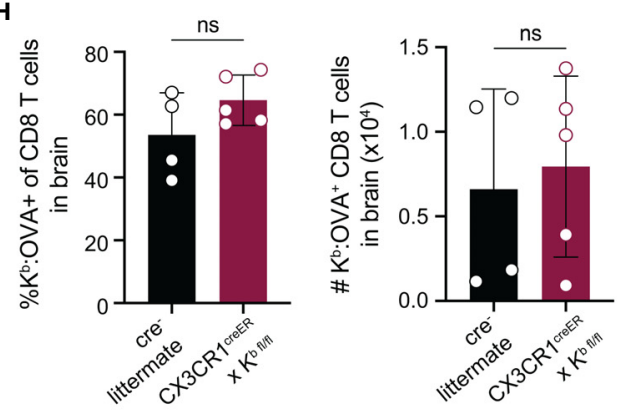

J

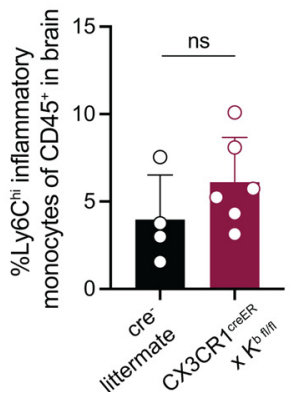

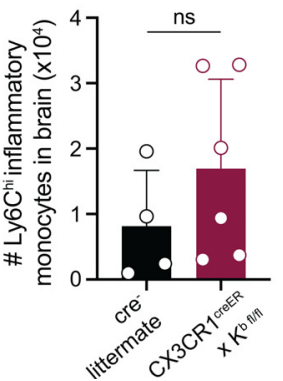

FIGURE 4 | Deletion of $\mathrm{H}-2 \mathrm{~K}^{\mathrm{b}}$ in CNS-myeloid cells does not impact CD8 T cell responses to the $\mathrm{K}^{\mathrm{b}}$ restricted antigen OVA ${ }_{257-264}$ during CNS-viral infection. Experimental strategy is identical to Figure $\mathbf{3 A}$, in which tamoxifen administration in $\mathrm{CX} 3 \mathrm{CR} 1^{\text {cre }} / \mathrm{K}^{\mathrm{b}}$ mice and cre ${ }^{-}$controls is followed by a 6 -week reconstitution period before intracranial (i.c.) infection with TMEV-OVA $257-264$. Spleens, lymph nodes, and brains were isolated and analyzed by flow cytometry at 7 days post infection to assess antiviral responses. (A, B) Quantification of $\mathrm{CD} 8^{+} \mathrm{T}$ cells (A) and $\mathrm{K}^{\mathrm{b}}$ : $\mathrm{OVA}_{257-264}{ }^{+} \mathrm{CD} 8 \mathrm{~T}$ cells (B) in the spleens of infected mice. (C) Proportion of naiive (CD44-CD62 $\left.\mathrm{L}^{+}\right)$, effector $\left(\mathrm{CD} 44^{+} \mathrm{CD} 62 \mathrm{~L}^{-}\right)$, and central memory $\left(\mathrm{CD} 44^{+} \mathrm{CD} 62 \mathrm{~L}^{+}\right) \mathrm{CD} 8 \mathrm{~T}$ cells in the spleens of infected mice. (D) Quantification of $\mathrm{CD} 8^{+} \mathrm{T}$ cells in the CNS-draining deep cervical lymph node (dCLN) of infected animals. (E) Representative flow cytometry plots, and (F) quantification of total CD8 T cells infiltrating the brain at 7 days post infection in $\mathrm{CX} 3 \mathrm{CR} 1^{\text {cre }} / \mathrm{K}^{\mathrm{b}}$ mice compared to controls. (G) Representative flow cytometry plots, and $(\mathbf{H})$ quantification of total $\mathrm{K}^{\mathrm{b}}$ : OVA $\mathrm{A}^{+} \mathrm{CD} 8$ T cells infiltrating the brain at 7 days post infection. (I) Quantification of CD4 T cells recovered from the brains of cre and $\mathrm{CX} 3 \mathrm{CR} 1^{\mathrm{cre}} / \mathrm{K}^{\mathrm{b}}$ mice during infection. (J) Inflammatory monocytes recovered from the brains of infected cre and $\mathrm{CX} 3 \mathrm{CR} 1^{\mathrm{cre}} / \mathrm{K}^{\mathrm{b}}$ mice are quantified. Data are shown as individual mice with mean from one independent experiment $(n=3-6)$ of $\geq 3$ experimental replicates. Error bars represent standard deviation. Two tailed Welch's $t$ test was used to assess statistical significance with $n s p \geq 0.05$. 
A

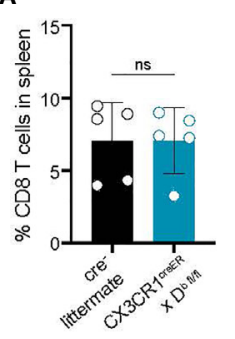

E

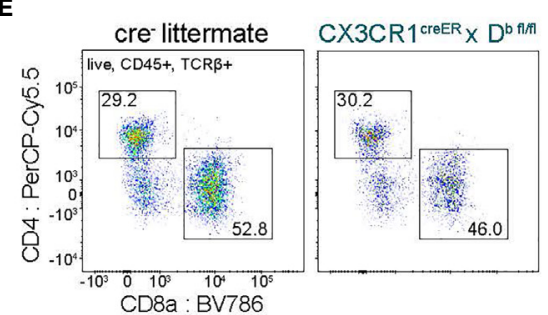

G

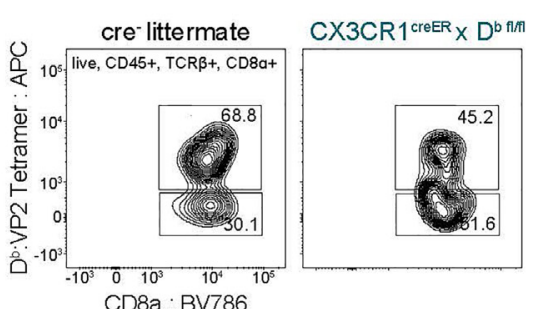

I

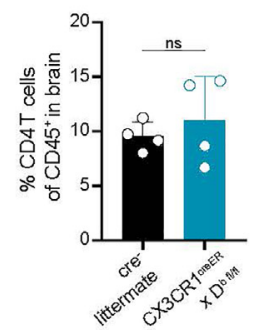

K

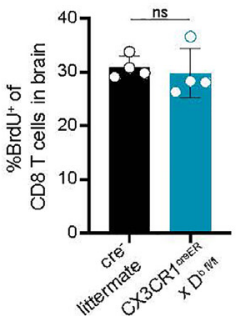

B

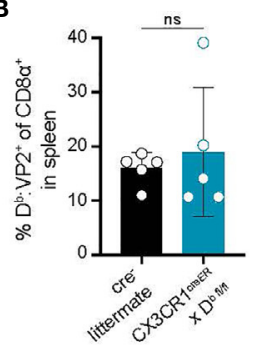

CX3CR1 $1^{\text {creER }} \times D^{\text {b fim }}$

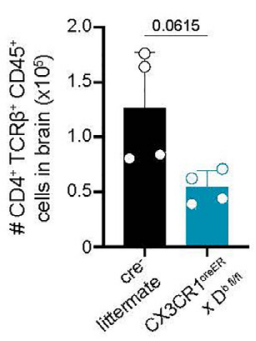

L

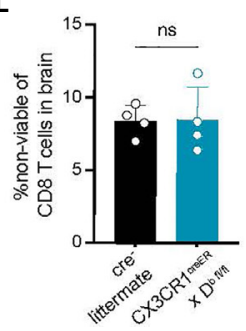

F

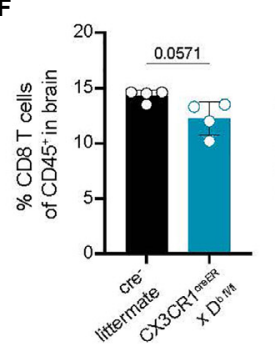

H
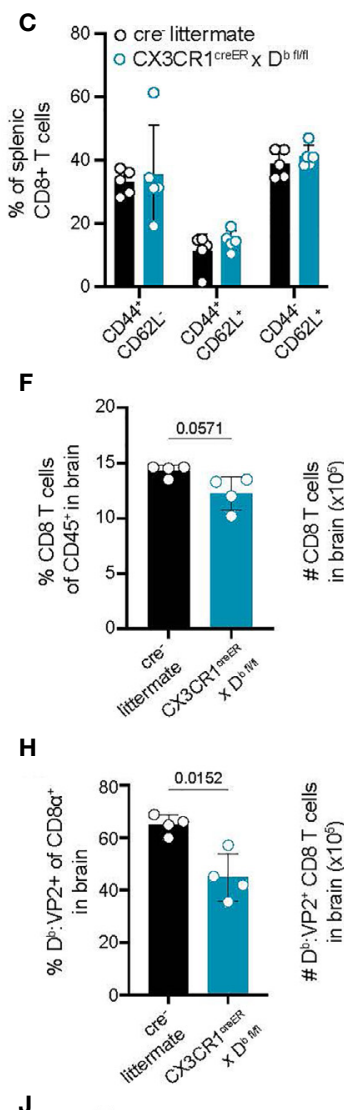

D
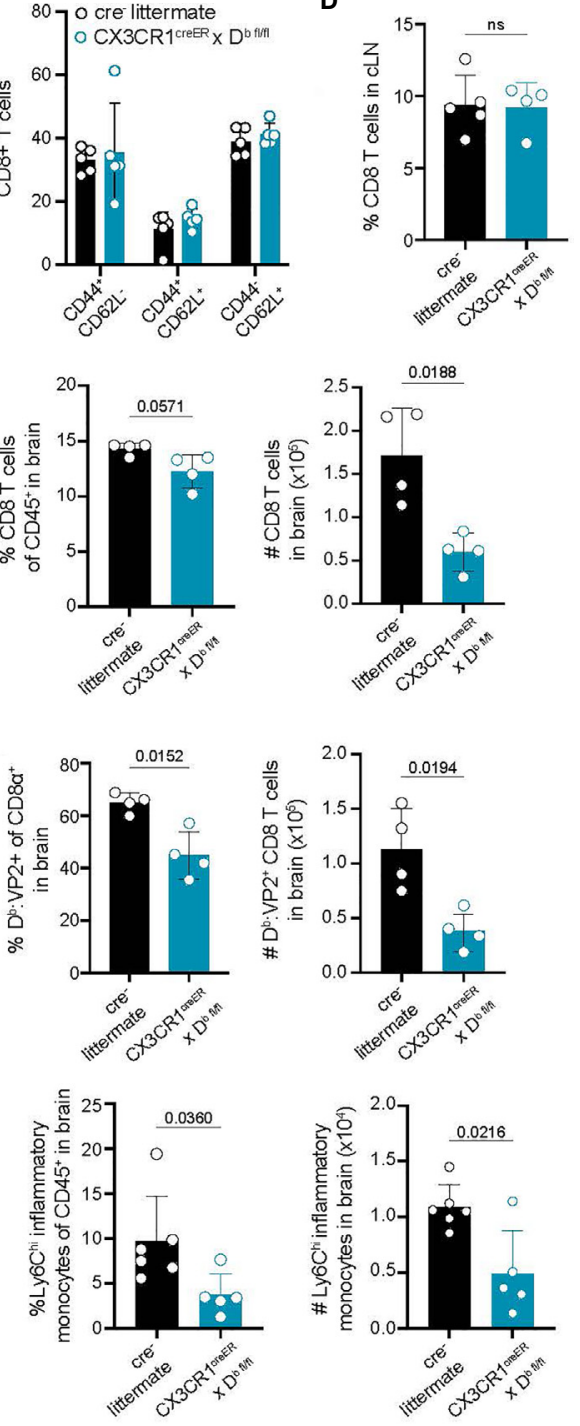

FIGURE 5 | Deletion of H-2D in CNS-myeloid cells reduces neuroinflammatory responses to the $D^{\mathrm{b}}$ restricted viral antigen VP2 ${ }_{121-130}$ during TMEV infection of the CNS. Experimental strategy is identical to Figure 3E, in which tamoxifen administration in CX3CR1 $1^{\text {cre }} / D^{\mathrm{b}}$ mice and cre controls is followed by a 6-week reconstitution period before i.c. infection with TMEV. Spleens, lymph nodes, and brains were analyzed by flow cytometry at 7 days post infection to assess antiviral responses.

(A, B) Quantification of CD8 ${ }^{+} T$ cells (A) and $D^{b}: V P 2^{+} \mathrm{CD} 8 \mathrm{~T}$ cells (B) in the spleens of infected mice. (C) Proportion of naiive $\left(\mathrm{CD}_{4} 4^{-} \mathrm{CD} 62 \mathrm{~L}^{+}\right)$, effector $\left(\mathrm{CD} 44^{+} \mathrm{CD} 62 \mathrm{~L}^{-}\right)$, and central memory (CD44 $\left.4^{+} \mathrm{CD} 62 \mathrm{~L}^{+}\right) \mathrm{CD} 8 \mathrm{~T}$ cells in the spleens of infected mice. (D) Quantification of $\mathrm{CD} 8^{+} \mathrm{T}$ cells in the dCLN of infected animals. (E) Representative flow cytometry plots, and (F) quantification of CD8 T cells infiltrating the brain at $7 \mathrm{dpi}$ in CX3CR1 ${ }^{\text {cre }} / \mathrm{D}^{\mathrm{b}}$ mice compared to controls. (G) Representative flow cytometry plots, and (H) quantification of total $\mathrm{D}^{\mathrm{b}}$ : VP2 $2^{+} \mathrm{CD} 8 \mathrm{~T}$ cells infiltrating the brain at 7 dpi. (I) Quantification of CD4 T cells recovered from the brains of mice during infection. (J) Inflammatory monocytes recovered from the brains of infected mice are quantified. (K) BrdU was administered intraperitoneally at day 6 post infection and BrdU incorporation into brain-infiltrating CD8 T cells was quantified. (L) Viability dye incorporation was measured in CD8 T cells isolated from the brains of infected mice. Data are shown as individual mice with mean from one independent experiment $(n=3-6)$ of $\geq 3$ experimental replicates. Error bars represent standard deviation. Two tailed Welch's $t$ test was used to assess statistical significance with $n s p \geq 0.05$. 
cells. However, to further rule out the contribution of peripheral APCs towards CD8 T cell infiltration, we sought to confirm our findings using a bone marrow chimeric approach. Cre littermates and $\mathrm{CX} 3 \mathrm{CR} 1^{\mathrm{cre}} / \mathrm{D}^{\mathrm{b}}$ animals were lethally irradiated and provided with wild type bone marrow, generating mice in which the $\mathrm{CX} 3 \mathrm{CR} 1^{\text {creER }}$ transgene is only present in the CNS immune compartment while hematopoietic cells are wild type (Figure 6A). In chimeric $\mathrm{CX} 3 \mathrm{CR} 1^{\mathrm{cre}} / \mathrm{D}^{\mathrm{b}}$ animals, we found that infiltration of total CD8 T cells to the brain was unaltered, while virus antigen specific $\mathrm{CD} 8 \mathrm{~T}$ cell brain infiltration was reduced (Figures 6B-D). Inflammatory monocyte infiltration was also reduced in $\mathrm{CX} 3 \mathrm{CR} 1^{\mathrm{cre}} / \mathrm{D}^{\mathrm{b}}$ chimeras (Figure $6 \mathrm{E}$ ). These findings suggest that CD8 $\mathrm{T}$ cell and inflammatory monocyte responses in the brain are specifically impacted by CNS-myeloid cell antigen presentation.

\section{CNS-Myeloid Cell Antigen Presentation to Virus-Antigen Specific CD8 T Cells via H-2D ${ }^{b}$ Impacts Brain Atrophy}

Given that CNS-myeloid cell deletion of $\mathrm{H}-2 \mathrm{D}^{\mathrm{b}}$ resulted in reduced immune infiltration at 7 days post TMEV infection, we next investigated outcomes of viral infection in $\mathrm{CX} 3 \mathrm{CR} 1^{\text {cre}}$ / $\mathrm{D}^{\mathrm{b}}$ animals. We found that $\mathrm{CX} 3 \mathrm{CR} 1^{\mathrm{cre}} / \mathrm{D}^{\mathrm{b}}$ animals experienced reduced weight loss during TMEV infection (Figure 7A). Next, we measured viral load over the course of infection. TMEV infection is generally cleared between 14-28 days post inoculation (33), and we determined that $\mathrm{CX} 3 \mathrm{CR} 1^{\mathrm{cre}} / \mathrm{D}^{\mathrm{b}}$ animals were able to clear infectious virus particle with the same kinetics as cre ${ }^{-}$controls despite reduced immune infiltration (Figure 7B), indicating that reduced immune infiltration when CNS-myeloid cells lacked expression of $\mathrm{H}$ $2 \mathrm{D}^{\mathrm{b}}$ did not impact clearance of infectious virus.

We next evaluated whether $\mathrm{CX} 3 \mathrm{CR} 1^{\mathrm{cre}} / \mathrm{D}^{\mathrm{b}}$ mice experienced altered neuropathological outcomes resulting from immune responses against TMEV. Cells of the innate immune system infiltrate the brain within 24 hours post TMEV infection and are linked to virus-independent apoptosis of hippocampal neurons and cognitive impairment (53). Both CX3CR $1^{\text {cre }} / \mathrm{D}^{\mathrm{b}}$ and $\mathrm{cre}$ animals that recovered from TMEV infection experienced loss of hippocampal neurons and cognitive impairment measured using the Novel Object Recognition test (NOR) (Figure S7), indicating that this outcome was not impacted by CNS-myeloid cell expression of $\mathrm{D}^{\mathrm{b}}$.

Notwithstanding, reduced immune infiltration could also impact brain atrophy associated with TMEV infection. We have previously shown that brain atrophy, which includes cellular loss, degradation of extracellular matrix, and/or loss of extracellular proteins, is dependent on the $\mathrm{D}^{\mathrm{b}}$ MHC class I molecule and $\mathrm{T}$ cells, suggesting a direct link between CD8 T cell responses and atrophy (38). Post-infectious brain atrophy was measured by lateral ventricle volume in a T2 weighted MRI. Consistent with previous reports, we found that cre controls experienced significant brain atrophy at $45 \mathrm{dpi}$ in comparison to naïve cre ${ }^{-}$counterparts (Figures $7 \mathrm{C}-\mathrm{E}$ ). CX3CR $1^{\mathrm{cre}} / \mathrm{D}^{\mathrm{b}}$ animals did not experience brain atrophy post infection when compared to naïve $\mathrm{CX} 3 \mathrm{CR} 1^{\mathrm{cre}} / \mathrm{D}^{\mathrm{b}}$ controls (Figures $7 \mathrm{C}-\mathbf{E}$ ). These results indicate that CNS-myeloid cell antigen presentation via $\mathrm{H}-2 \mathrm{D}^{\mathrm{b}}$ contributes to the onset of brain atrophy induced by TMEV infection.

\section{DISCUSSION}

The role of local antigen presentation in promoting $\mathrm{T}$ cell infiltration of the CNS during neuroinflammation is not entirely understood. Herein, we present a characterization of APCs in the naïve and virally infected brain. We identify CNSresident myeloid cells, microglia and perivascular macrophages, as local APCs that become activated and upregulate MHC class I molecules during infection. We analyzed the ability of CNSmyeloid cells to promote CD8 $\mathrm{T}$ cell trafficking into the brain parenchyma upon viral challenge with both $\mathrm{K}^{\mathrm{b}}$ or $\mathrm{D}^{\mathrm{b}}$ restricted antigens, and determined differential requirements for $\mathrm{K}^{\mathrm{b}}$ and $\mathrm{D}^{\mathrm{b}}$ expression during acute viral infection. Further, we determined that reducing the antiviral immune response attenuated the development of brain atrophy while still promoting mechanisms of viral clearance, implying that local antigen presentation augments neuropathology in the CNS. Our work provides evidence that CNS-myeloid cells can act as APCs in vivo to mediate CNS inflammation.

Microglia and CNS-macrophages play a key role in antiviral defenses during CNS viral infections and can promote $\mathrm{T}$ cell effector functions in the CNS (54). The field has relied heavily on whole cell depletion experiments to assess the contribution of microglia to antiviral defenses. Caution is necessary when interpreting studies employing CSF1R inhibitors to deplete microglia during viral infection, as off-target effects on peripheral immunity were observed in our study and others $(55,56)$. This aside, Waltl et al. revealed microglia are key in controlling TMEV propagation and clearance in C57BL/6 mice, positing this was likely due to microglial:T cell interactions (57). Our data demonstrate that CNS-myeloid cells are positioned to present antigen to modulate antigen-specific CD8 $\mathrm{T}$ cells attempting to infiltrate the brain through the $\mathrm{BBB}$ during TMEV infection. Importantly, CNS-myeloid cells are not directly infected by TMEV, but may cross-present exogenous antigens such as viral peptides acquired from adjacent infected neurons to impact CD8 T cell infiltration of the CNS during infection $(24,58)$. Our work investigating antigen presentation by CNS-myeloid cells during TMEV infection using transgenic mice adds to this body of literature, and extends the possibility that CNS-myeloid cells cross-present antigen derived from infected neurons to modulate CD8 $\mathrm{T}$ cell infiltration in response to infection.

MHC class I molecules play multiple roles in immunity, including regulation of CD8 $\mathrm{T}$ cell development and cytotoxic activity. In the CNS, MHC class I plays a key role in neuronal development, synaptic plasticity, and axonal regeneration (59). Nonetheless, in our analysis, CNS-myeloid cells exhibited no obvious development or activation defects upon loss of MHC class I expression. Whether deletion of MHC class I by CNSmyeloid cells during embryogenesis impacts CNS development 
A

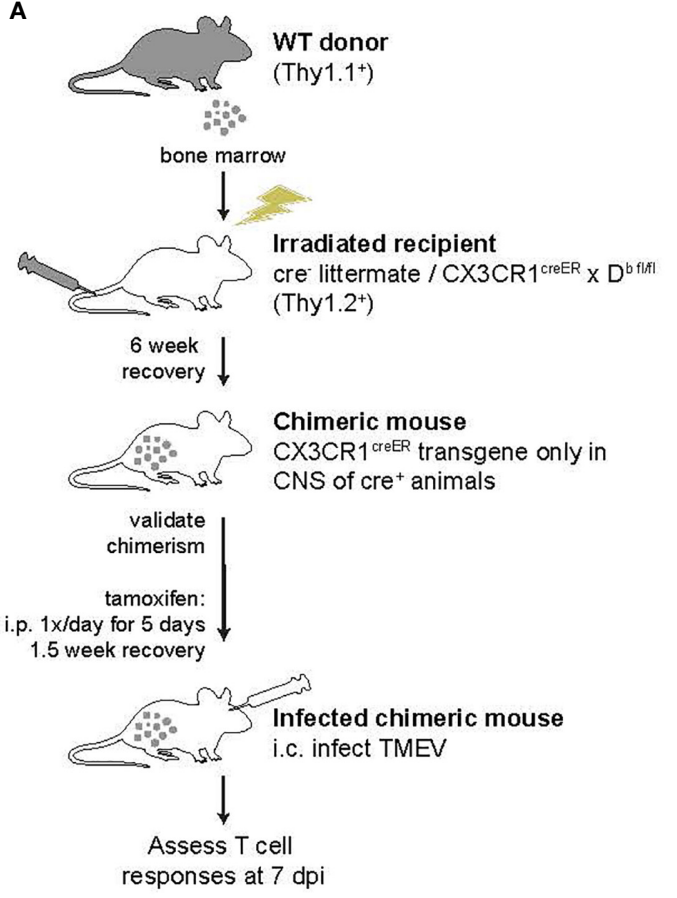

D

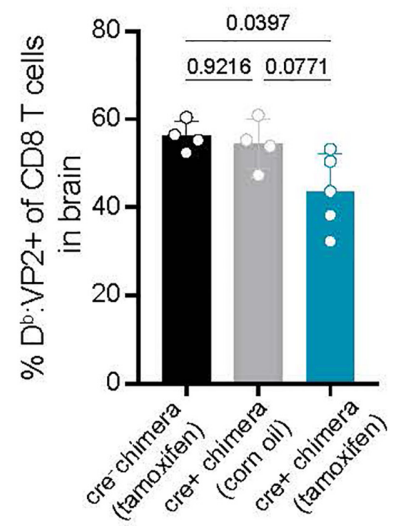

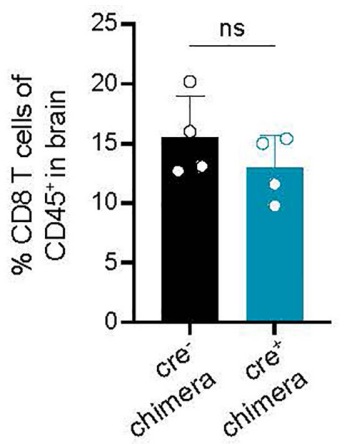

C

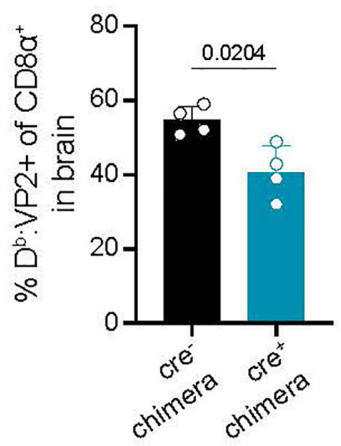

E

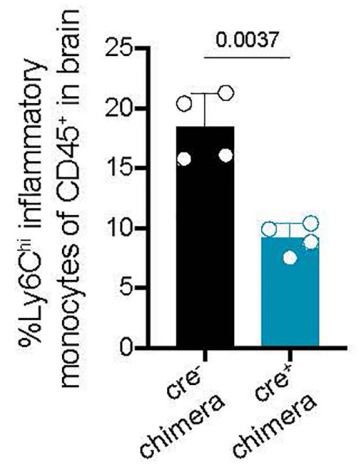

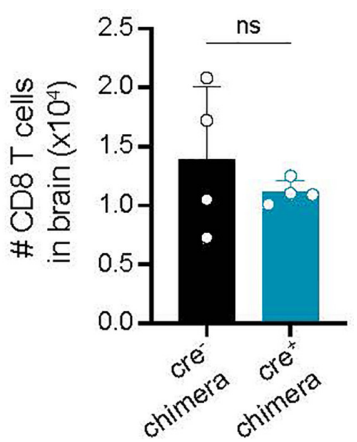
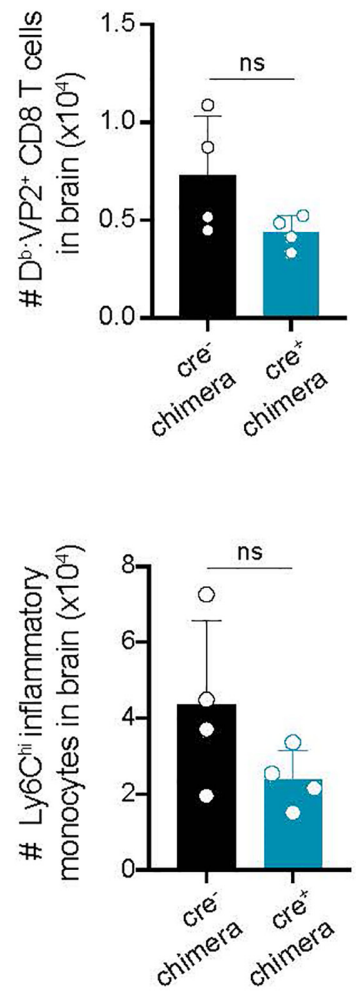

FIGURE 6 | Deletion of $\mathrm{H}-2 \mathrm{D}^{\mathrm{b}}$ in only CNS-myeloid cells reduces immune infiltration following TMEV infection. (A) Bone marrow chimeras were generated by lethal irradiation of recipient cre- littermates and $\mathrm{CX} 3 \mathrm{CR} 1^{\mathrm{cre}} / \mathrm{D}^{\mathrm{b}}$ mice followed by reconstitution with $\mathrm{WT}$ congenic (Thy1.1) bone marrow. Six weeks later, after validation of chimerism, chimeric mice received intraperitoneal tamoxifen treatment. After recovery, chimeric mice were intracranially infected with TMEV to assess antiviral responses. (B-C) The frequency and number of CD8 T cells (B) and VP2-specific CD8 T cells (C) recovered from the brains of cre and CX3CR1 ${ }^{\text {cre }} / D^{\mathrm{b}}$ mice. (D) A new set of chimeras were generated with the addition of a CX3CR1 $1^{\text {cre }} / D^{b}$ group treated with vehicle control. The frequency of $D^{b}: V P 2^{+} C D 8 T$ cells recovered

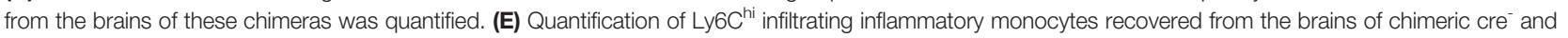
$\mathrm{CX} 3 \mathrm{CR}_{1}{ }^{\mathrm{cre}} / \mathrm{D}^{\mathrm{b}}$ mice. Data are shown as individual mice with mean from one independent experiment $(n=3-6)$ of $\geq 3$ experimental replicates. Error bars represent standard deviation. Two tailed Welch's $t$ test or one-way ANOVA with Tukey's correction were used to assess statistical significance with ns $p \geq 0.05$.

remains to be studied. MHC class I molecules are also major inhibitory receptors for NK cells, and lack of expression can trigger NK-mediated killing (60). However, our data indicate that CNS-myeloid cells lacking $\mathrm{K}^{\mathrm{b}}$ and $\mathrm{D}^{\mathrm{b}}$ were not reduced in population and hence are not killed by NK cells. This is in contrast to what has been reported for $\beta 2 \mathrm{~m}$ floxed mice, a model that ablates $\mathrm{H}-2 \mathrm{~K}^{\mathrm{b}} / \mathrm{H}-2 \mathrm{D}^{\mathrm{b}}$ as well as nonclassical MHC class I molecules and can impact NK cell licensing and recognition (58). We therefore contend that our cre-lox strategy specific for $\mathrm{K}^{\mathrm{b}}$ and $\mathrm{D}^{\mathrm{b}}$ provides a means to study discrete contributions of each MHC class I molecule in isolation without off-target effects from Class Ib molecules.

The data presented herein demonstrate that CNS-myeloid cells are required for immune infiltration of the brain in a 
A

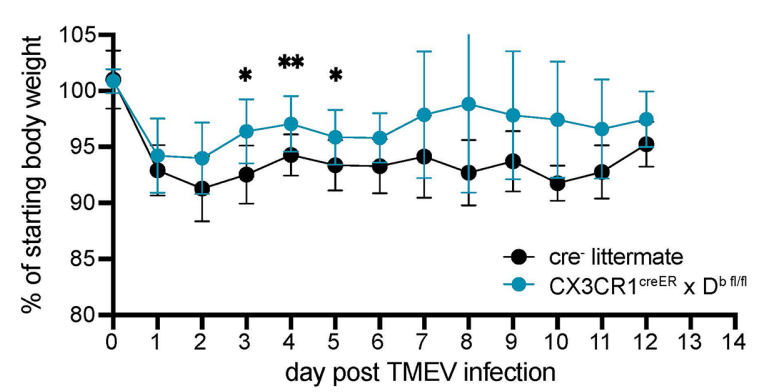

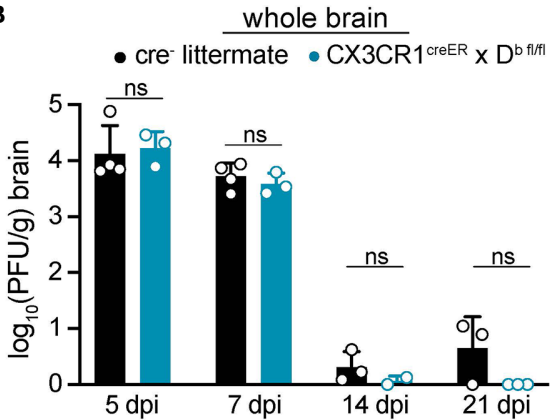

C

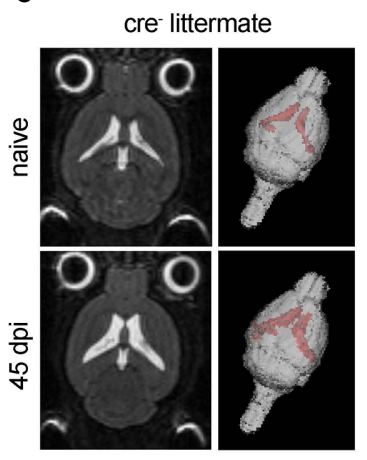

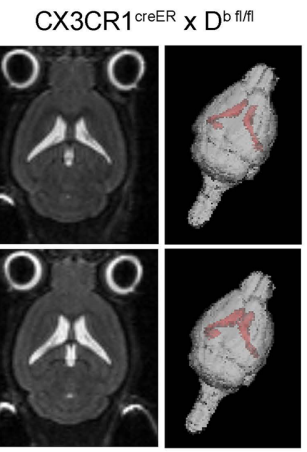

D

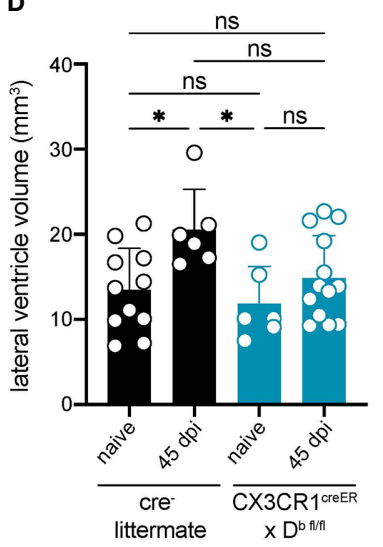

E

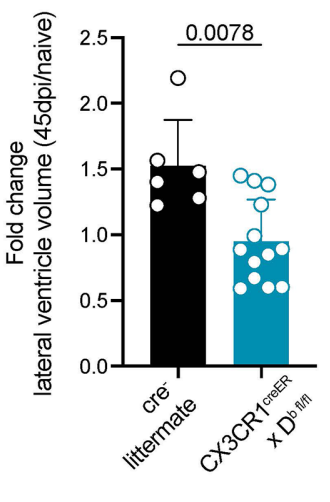

FIGURE 7 | H-2D $\mathrm{D}^{\mathrm{b}}$ expression by CNS-myeloid cells impacts antiviral immunity and brain atrophy. Experimental strategy is identical to Figure $\mathbf{3 E}$, in which tamoxifen administration in $\mathrm{CX} 3 \mathrm{CR}^{\mathrm{cre}} / \mathrm{D}^{\mathrm{b}}$ mice and cre controls is followed by a 6-week reconstitution period before i.c. infection with TMEV. (A) Weight loss over the course of infection is measured in cre- and CX3CR1 ${ }^{\text {cre }} / \mathrm{D}^{\mathrm{b}}$ mice. (B) Infectious viral load in whole brain homogenates at 5-, 7-, 14-, and 21-days post infection is measured by plaque assay in cre and $\mathrm{CX} 3 \mathrm{CR} 1^{\text {cre }} / \mathrm{D}^{\mathrm{b}}$ mice. (C) Representative $2 \mathrm{D}$ images and $3 \mathrm{D}$ renderings of lateral ventricle volumes obtained by $\mathrm{T} 2$ weighted $\mathrm{MRI}$ of $\mathrm{cre}^{-}$and $\mathrm{CX} 3 \mathrm{CR} 1^{\mathrm{cre}} / \mathrm{D}^{\mathrm{b}}$ mice during naïve conditions and after recovery from TMEV infection (45 dpi). Images were analyzed using Analyze 12.0 (D) Lateral ventricle volume is quantified for naïve and TMEV-recovered cre controls and CX3CR $1^{\text {cre }} / \mathrm{D}^{\mathrm{b}}$ mice. (E) Fold change in lateral ventricle volume from naïve to $45 \mathrm{dpi}$ is quantified for TMEV-recovered cre ${ }^{-}$controls and $C X 3 C R 1^{\text {cre }} / D^{\mathrm{b}}$ mice. Data are shown as individual mice with mean from one independent experiment $(n=3-13)$ of $\geq 2$ experimental replicates. Error bars represent standard deviation. Two tailed Welch's $t$ test or one-way ANOVA with Tukey's correction were used to assess statistical significance with $\mathrm{ns} \mathrm{p} \geq 0.05 .{ }^{*}$ denotes $\mathrm{P}<0.05,{ }^{* *}$ denotes $\mathrm{P}<0.001$.

context-dependent manner. The difference between $\mathrm{K}^{\mathrm{b}}$ and $\mathrm{D}^{\mathrm{b}}$ may be explained by the importance of the $\mathrm{H}-2 \mathrm{D}^{\mathrm{b}}$ molecule in driving CD8 T cell recognition of the immunodominant epitope of TMEV. However, the engineered TMEV-OVA virus experiences an attenuation in virulence as compared to the wt virus (34), potentially impacting our results. Nonetheless, we posit that $\mathrm{K}^{\mathrm{b}} / \mathrm{D}^{\mathrm{b}}$ differences extend beyond CD8 $\mathrm{T}$ cell recognition of TMEV/TMEV-OVA and infer differences between $\mathrm{K}^{\mathrm{b}}$ and $\mathrm{D}^{\mathrm{b}}$ during neuroinflammation. We found that $\mathrm{K}^{\mathrm{b}}$ and $\mathrm{D}^{\mathrm{b}}$ were expressed in differing levels by immune cells in the naïve and infected CNS. The $\mathrm{H}-2 \mathrm{~K}$ and $\mathrm{H}-2 \mathrm{D}$ genes are differentially expressed by unique subsets of neurons in the developing and mature CNS, indicating different functionality (61). Whether $\mathrm{K}^{\mathrm{b}}$ and $\mathrm{D}^{\mathrm{b}}$ differentially impact antigen presentation during other neuroinflammatory conditions remains to be studied.

In this study, CNS-myeloid cell antigen presentation impacted antiviral CD8 $\mathrm{T}$ cell and inflammatory monocyte infiltration of the brain. CD8 $\mathrm{T}$ cells have the ability to secrete chemokines that attract pathogenic monocytes during lymphocytic choriomeningitis virus (LCMV) infection (62). Our findings contend that recruitment of monocytes to the brain is augmented by antigen presentation and CD8 $\mathrm{T}$ cell responses, and CD8 $\mathrm{T}$ cells may produce chemoattractants such as CCL2 to promote monocytic brain infiltration (63). Despite this, CNS-myeloid cell antigen presentation did not alter hippocampal neuron damage, perhaps due to intact early innate immune processes with the capacity to contribute to neuronal loss (53). Mice with defects in CNS-myeloid cell antigen presentation were however protected from brain atrophy. Our working model is that damage to hippocampal neurons occurs within the first few days as a result of innate immune processes, while local antigen presentation via $\mathrm{H}-2 \mathrm{D}^{\mathrm{b}}$ drives CD8 $\mathrm{T}$ cells that contribute to brain atrophy in regions outside of the hippocampus. It is therefore conceivable that brain atrophy can be attenuated by reducing antiviral CD8 $\mathrm{T}$ cell 
infiltration, and CD8 T cell infiltration is likely mediated by local antigen presentation by CNS-myeloid cells. Given the recent link between CD8 T cells and neurodegenerative conditions such as Alzheimer's disease and Parkinson's disease, our findings are highly relevant to neurologic disease (8-10).

Our findings suggest that additional APCs must play a role in antiviral immune infiltration of the CNS. Meningeal APCs can promote CD4 $\mathrm{T}$ cell infiltration of the inflamed CNS (64). However, meningeal antigen presentation to CD8 $\mathrm{T}$ cells remains to be investigated. Critical APCs may also include glial cells, such as oligodendrocyte precursor cells (OPCs), which cross present antigen via MHC class I when exposed to IFN $\gamma$ during demyelination (65). The contribution of additional APCs to promoting CD8 $\mathrm{T}$ cell infiltration of the inflamed CNS will be the topic of further investigation.

The classical view of antiviral $\mathrm{T}$ cell responses posits that once activated CD8 $\mathrm{T}$ cells search for cognate peptide presented on MHC class I by infected cells after infiltrating the tissue. While once controversial, direct CD8 T cell engagement with neurons during neuroinflammation is becoming more widely accepted and may play a critical role in pathogen clearance. Our group has observed CD8 T cells forming immune synapses with TMEV infected neurons during acute infection (66). Similarly, latent herpes simplex virus 1 (HSV) reactivation is modulated by CD 8 $\mathrm{T}$ cells recognizing cognate antigen presented by neuronal MHC class I (5). Finally, neuronal antigen presentation is required for CD8 $\mathrm{T}$ cell mediated clearance of the Toxoplasma gondii parasite in multiple phases of infection (67). It is unknown whether neuronal MHC class I plays a key role in CD8 T cell containment of TMEV or TMEV-OVA, though these studies are ongoing. Overall, our results suggest that CNS-myeloid cells play a role in promoting CD8 $\mathrm{T}$ cell infiltration of the infected CNS in an antigen-dependent manner, but compensatory mechanisms exist that promote viral clearance. Thus, MHC class I expression on multiple CNS cell types may be required for unique immunological mechanisms that promote CD8 T cell infiltration through brain barriers and CD8 $\mathrm{T}$ cell mediated viral clearance in a cell-specific manner.

In conclusion, our study sheds light on the importance of CNS-myeloid cell antigen presentation during CNS viral infection and reveals marked differences between the $\mathrm{H}-2 \mathrm{~K}^{\mathrm{b}}$ and $\mathrm{H}-2 \mathrm{D}^{\mathrm{b}}$ MHC class I molecules. These findings have important implications for our understanding of CD8 $\mathrm{T}$ cell mediated antiviral immunity and immunopathology in the CNS, as considerable focus has been exclusively placed on antigen presentation by the $\mathrm{H}-2 \mathrm{~K}^{\mathrm{b}}$ molecule due to the wide availability of reagents and model antigens. Our study also emphasizes the importance of MHC class I antigen presentation in the CNS in the context of neurodegeneration. Further investigation of the roles of specific MHC class I alleles and antigen presentation by discrete cell types will be crucial, especially given increasing literature linking CD8 $\mathrm{T}$ cell responses to aging and neurodegenerative diseases. These studies should offer new insights into the therapeutic potential of targeting CNS infiltration of antigenspecific $\mathrm{T}$ cells as a means to attenuate $\mathrm{T}$ cell mediated brain atrophy in neurological disease $(8-10,68)$.

\section{DATA AVAILABILITY STATEMENT}

The original contributions presented in the study are included in the article/Supplementary Material. Further inquiries can be directed to the corresponding author.

\section{ETHICS STATEMENT}

The animal study was reviewed and approved by Mayo Clinic Institutional Animal Care and Use Committee and the National Institutes of Health guidelines.

\section{AUTHOR CONTRIBUTIONS}

EG, CF, CL, and KA designed and performed the majority of experiments. LY, CM, RK, ZT, FJ, and MH performed some experiments and/or provided feedback towards experimental design and manuscript conceptualization. EG and AJ wrote the manuscript. All authors have read the manuscript and provided essential feedback, and all co-authors agree with the data presented. All authors contributed to the article and approved the submitted version.

\section{FUNDING}

The authors received funding for this work through NIH R01 NS103212 (AJ) and RF1 NS122174 (AJ).

\section{ACKNOWLEDGMENTS}

We would like to thank Drs. Charles Howe and LongJun-Wu for their crucial help in preparing this manuscript and sharing resources. We would like to thank Dr. John Fryer for discussion and sharing of transgenic mouse choices to study myeloid cells. We would like to thank Manling Xie, Jiaying (Fiona) Zheng, and Dr. Upkong Eyo for their technical assistance and help in designing experiments. We would also like the thank the NIH tetramer core facility for providing tetramers that were used in this work. Biorender.com was used to create the graphical abstract and some schematics.

\section{SUPPLEMENTARY MATERIAL}

The Supplementary Material for this article can be found online at: https://www.frontiersin.org/articles/10.3389/fimmu.2021. 726421/full\#supplementary-material 


\section{REFERENCES}

1. Ransohoff RM, Engelhardt B. The Anatomical and Cellular Basis of Immune Surveillance in the Central Nervous System. Nat Rev Immunol (2012) 12:62335. doi: $10.1038 /$ nri3265

2. Klein RS, Hunter CA. Protective and Pathological Immunity During Central Nervous System Infections. Immunity (2017) 46:891-909. doi: 10.1016/j.immuni.2017.06.012

3. Ai S, Klein RS. Update on T Cells in the Virally Infected Brain: Friends and Foes. Curr Opin Neurol (2020) 33:405-12. doi: 10.1097/WCO.0000000000000825

4. Becher B, Bechmann I, Greter M. Antigen Presentation in Autoimmunity and CNS Inflammation: How T Lymphocytes Recognize the Brain. J Mol Med (Berl) (2006) 84:532-43. doi: 10.1007/s00109-006-0065-1

5. Liu T, Khanna KM, Chen X, Fink DJ, Hendricks RL. CD8(+) T Cells can Block Herpes Simplex Virus Type 1 (HSV-1) Reactivation From Latency in Sensory Neurons. J Exp Med (2000) 191:1459-66. doi: 10.1084/jem.191.9.1459

6. Shrestha B, Samuel MA, Diamond MS. CD8+ T Cells Require Perforin to Clear West Nile Virus From Infected Neurons. J Virol (2006) 80:119-29. doi: 10.1128/JVI.80.1.119-129.2006

7. Wagner CA, Roque PJ, Mileur TR, Liggitt D, Goverman JM. Myelin-Specific CD8+ T Cells Exacerbate Brain Inflammation in CNS Autoimmunity. J Clin Invest (2020) 130:203-13. doi: 10.1172/JCI132531

8. Gate D, Saligrama N, Leventhal O, Yang AC, Unger MS, Middeldorp J, et al. Clonally Expanded CD8 T Cells Patrol the Cerebrospinal Fluid in Alzheimer's Disease. Nature (2020) 577:399-404. doi: 10.1038/s41586-019-1895-7

9. Lindestam Arlehamn CS, Dhanwani R, Pham J, Kuan R, Frazier A, Rezende Dutra J, et al. Alpha-Synuclein-Specific T Cell Reactivity Is Associated With Preclinical and Early Parkinson's Disease. Nat Commun (2020) 11:1875. doi: 10.1038/s41467-020-15626-w

10. Galiano-Landeira J, Torra A, Vila M, Bove J. CD8 T Cell Nigral Infiltration Precedes Synucleinopathy in Early Stages of Parkinson's Disease. Brain (2020) 143:3717-33. doi: 10.1093/brain/awaa269

11. Aspelund A, Antila S, Proulx ST, Karlsen TV, Karaman S, Detmar M, et al. A Dural Lymphatic Vascular System That Drains Brain Interstitial Fluid and Macromolecules. J Exp Med (2015) 212:991-9. doi: 10.1084/jem.20142290

12. Louveau A, Smirnov I, Keyes TJ, Eccles JD, Rouhani SJ, Peske JD, et al. Structural and Functional Features of Central Nervous System Lymphatic Vessels. Nature (2015) 523:337-41. doi: 10.1038/nature14432

13. Tritz ZP, Orozco RC, Malo CS, Ayasoufi K, Fain CE, Khadka RH, et al. Conditional Silencing of H-2D(B) Class I Molecule Expression Modulates the Protective and Pathogenic Kinetics of Virus-Antigen-Specific CD8 T Cell Responses During Theiler's Virus Infection. J Immunol (2020) 205:1228-38. doi: 10.4049/jimmunol.2000340

14. Malo CS, Huggins MA, Goddery EN, Tolcher HMA, Renner DN, Jin F, et al. Non-Equivalent Antigen Presenting Capabilities of Dendritic Cells and Macrophages in Generating Brain-Infiltrating CD8 (+) T Cell Responses. Nat Commun (2018) 9:633. doi: 10.1038/s41467-018-03037-x

15. Waisman A, Johann L. Antigen-Presenting Cell Diversity for T Cell Reactivation in Central Nervous System Autoimmunity. J Mol Med (Berl) (2018) 96:1279-92. doi: 10.1007/s00109-018-1709-7

16. Schlager C, Körner H, Krueger M, Vidoli S, Haberl M, Mielke D, et al. Effector T-Cell Trafficking Between the Leptomeninges and the Cerebrospinal Fluid. Nature (2016) 530:349-53. doi: 10.1038/nature16939

17. Bartholomaus I, Kawakami N, Odoardi F, Schläger C, Miljkovic D, Ellwart JW, et al. Effector T Cell Interactions With Meningeal Vascular Structures in Nascent Autoimmune CNS Lesions. Nature (2009) 462:94-8. doi: 10.1038/nature08478

18. Fletcher JM, Lalor SJ, Sweeney CM, Tubridy N, Mills KH. T Cells in Multiple Sclerosis and Experimental Autoimmune Encephalomyelitis. Clin Exp Immunol (2010) 162:1-11. doi: 10.1111/j.1365-2249.2010.04143.x

19. Wolf Y, Shemer A, Levy-Efrati L, Gross M, Kim JS, Engel A, et al. Microglial MHC Class II Is Dispensable for Experimental Autoimmune Encephalomyelitis and Cuprizone-Induced Demyelination. Eur J Immunol (2018) 48:1308-18. doi: 10.1002/eji.201847540

20. Mundt S, Mrdjen D, Utz SG, Greter M, Schreiner B, Becher B. Conventional DCs Sample and Present Myelin Antigens in the Healthy CNS and Allow Parenchymal T Cell Entry to Initiate Neuroinflammation. Sci Immunol (2019) 4: eaau8380. doi: 10.1126/sciimmunol.aau8380

21. Jordao MJC, Sankowski R, Brendecke SM, Sagar, Locatelli G, YH T, et al. Single-Cell Profiling Identifies Myeloid Cell Subsets With Distinct Fates
During Neuroinflammation. Science (2019) 363:eaat7554. doi: 10.1126/ science.aat 7554

22. Herz J, Johnson KR, McGavern DB. Therapeutic Antiviral T Cells Noncytopathically Clear Persistently Infected Microglia After Conversion Into Antigen-Presenting Cells. J Exp Med (2015) 212:1153-69. doi: 10.1084/ jem.20142047

23. Jarry U, Jeannin P, Pineau L, Donnou S, Delneste Y, Couez D. Efficiently Stimulated Adult Microglia Cross-Prime Naive CD8+ T Cells Injected in the Brain. Eur J Immunol (2013) 43:1173-84. doi: 10.1002/eji.201243040

24. Beauvillain C, Donnou S, Jarry U, Scotet M, Gascan H, Delneste Y, et al. Neonatal and Adult Microglia Cross-Present Exogenous Antigens. Glia (2008) 56:69-77. doi: 10.1002/glia.20565

25. Pope JG, Vanderlugt CL, Rahbe SM, Lipton HL, Miller SD. Characterization of and Functional Antigen Presentation by Central Nervous System Mononuclear Cells From Mice Infected With Theiler's Murine Encephalomyelitis Virus. J Virol (1998) 72:7762-71. doi: 10.1128/JVI.72.10.7762-7771.1998

26. Pirko I, Johnson AJ, Chen Y, Lindquist DM, Lohrey AK, Ying J, et al. Brain Atrophy Correlates With Functional Outcome in a Murine Model of Multiple Sclerosis. Neuroimage (2011) 54:802-6. doi: 10.1016/j.neuroimage. 2010.08.055

27. Pirko I, Gamez J, Johnson AJ, Macura SI, Rodriguez M. Dynamics of MRI Lesion Development in an Animal Model of Viral-Induced Acute Progressive CNS Demyelination. Neuroimage (2004) 21:576-82. doi: 10.1016/ j.neuroimage.2003.09.037

28. Buenz EJ, Rodriguez M, Howe CL. Disrupted Spatial Memory Is a Consequence of Picornavirus Infection. Neurobiol Dis (2006) 24:266-73. doi: $10.1016 /$ j.nbd.2006.07.003

29. Getts MT, Richards MH, Miller SD. A Critical Role for Virus-Specific CD8(+) CTLs in Protection From Theiler's Virus-Induced Demyelination in DiseaseSusceptible SJL Mice. Virology (2010) 402:102-11. doi: 10.1016/j.virol.2010.02.031

30. Mendez-Fernandez YV, Johnson AJ, Rodriguez M, Pease LR. Clearance of Theiler's Virus Infection Depends on the Ability to Generate a CD8+ T Cell Response Against a Single Immunodominant Viral Peptide. Eur J Immunol (2003) 33:2501-10. doi: 10.1002/eji.200324007

31. Lin X, Kariuki Njenga M, Johnson AJ, Pavelko KD, David CS, Pease LR, et al. Transgenic Expression of Theiler's Murine Encephalomyelitis Virus Genes in H-2(B) Mice Inhibits Resistance to Virus-Induced Demyelination. J Virol (2002) 76:7799-811. doi: 10.1128/JVI.76.15.7799-7811.2002

32. Johnson AJ, Njenga MK, Hansen MJ, Kuhns ST, Chen L, Rodriguez M, et al. Prevalent Class I-Restricted T-Cell Response to the Theiler's Virus Epitope Db : VP2121-130 in the Absence of Endogenous CD4 Help, Tumor Necrosis Factor Alpha, Gamma Interferon, Perforin, or Costimulation Through CD28. J Virol (1999) 73:3702-8. doi: 10.1128/JVI.73.5.3702-3708.1999

33. Gerhauser I, Hansmann F, Ciurkiewicz M, Loscher W, Beineke A. Facets of Theiler's Murine Encephalomyelitis Virus-Induced Diseases: An Update. Int J Mol Sci (2019) 20:448. doi: 10.3390/ijms20020448

34. Pavelko KD, Girtman MA, Mitsunaga Y, Mendez-Fernandez YV, Bell MP, Hansen MJ, et al. Theiler's Murine Encephalomyelitis Virus as a Vaccine Candidate for Immunotherapy. PloS One (2011) 6:e20217. doi: 10.1371/ journal.pone.0020217

35. Cumba Garcia LM, Huseby Kelcher AM, Malo CS, Johnson AJ. Superior Isolation of Antigen-Specific Brain Infiltrating T Cells Using Manual Homogenization Technique. J Immunol Methods (2016) 439:23-8. doi: 10.1016/j.jim.2016.09.002

36. Oleszak EL, Leibowitz JL, Rodriguez M. Isolation and Characterization of Two Plaque Size Variants of Theiler's Murine Encephalomyelitis Virus (DA Strain). J Gen Virol (1988) 69(Pt 9):2413-8. doi: 10.1099/0022-1317-69-92413

37. Buenz EJ, Sauer BM, Lafrance-Corey RG, Deb C, Denic A, German CL, et al. Apoptosis of Hippocampal Pyramidal Neurons Is Virus Independent in a Mouse Model of Acute Neurovirulent Picornavirus Infection. Am J Pathol (2009) 175:668-84. doi: 10.2353/ajpath.2009.081126

38. Huseby Kelcher AM, Atanga PA, Gamez JD, Cumba Garcia LM, Teclaw SJ, Pavelko KD, et al. Brain Atrophy in Picornavirus-Infected FVB Mice Is Dependent on the H-2D(B) Class I Molecule. FASEB J (2017) 31:2267-75. doi: 10.1096/fj.201601055R

39. Haruwaka K, Ikegami A, Tachibana Y, Ohno N, Konishi H, Hashimoto A, et al. Dual Microglia Effects on Blood Brain Barrier Permeability Induced by 
Systemic Inflammation. Nat Commun (2019) 10:5816. doi: 10.1038/s41467019-13812-z

40. Ferreira TA, Blackman AV, Oyrer J, Jayabal S, Chung AJ, Watt AJ, et al. Neuronal Morphometry Directly From Bitmap Images. Nat Methods (2014) 11:982-4. doi: 10.1038/nmeth.3125

41. Arganda-Carreras I, Fernandez-Gonzalez R, Munoz-Barrutia A, Ortiz-DeSolorzano C. 3D Reconstruction of Histological Sections: Application to Mammary Gland Tissue. Microsc Res Tech (2010) 73:1019-29. doi: 10.1002/ jemt.20829

42. Schindelin J, Arganda-Carreras I, Frise E, Kaynig V, Longair M, Pietzsch T, et al. Fiji: An Open-Source Platform for Biological-Image Analysis. Nat Methods (2012) 9(7):676-82. doi: 10.1038/nmeth.2019

43. McInnes L, Healy J, Melville J. UMAP: Uniform Manifold Approximation and Projection for Dimension Reduction. arXiv (2020) 1802.03426 [stat.ML].

44. Lyman MA, Myoung J, Mohindru M, Kim BS. Quantitative, Not Qualitative, Differences in CD8(+) T Cell Responses to Theiler's Murine Encephalomyelitis Virus Between Resistant C57BL/6 and Susceptible SJL/J Mice. Eur J Immunol (2004) 34:2730-9. doi: 10.1002/eji.200324811

45. Goldmann T, Wieghofer P, Jordão MJ, Prutek F, Hagemeyer N, Frenzel K, et al. Origin, Fate and Dynamics of Macrophages at Central Nervous System Interfaces. Nat Immunol (2016) 17:797-805. doi: 10.1038/ni.3423

46. Morrison HW, Filosa JA. A Quantitative Spatiotemporal Analysis of Microglia Morphology During Ischemic Stroke and Reperfusion. J Neuroinflamm (2013) 10:4. doi: 10.1186/1742-2094-10-4

47. Keren-Shaul H, Spinrad A, Weiner A, Matcovitch-Natan O, Dvir-Szternfeld R, Ulland TK, et al. A Unique Microglia Type Associated With Restricting Development of Alzheimer's Disease. Cell (2017) 169:1276-90.e1217. doi: 10.1016/j.cell.2017.05.018

48. Elmore MR, Najafi AR, Koike MA, Dagher NN, Spangenberg EE, Rice RA, et al. Colony-Stimulating Factor 1 Receptor Signaling Is Necessary for Microglia Viability, Unmasking a Microglia Progenitor Cell in the Adult Brain. Neuron (2014) 82:380-97. doi: 10.1016/j.neuron.2014.02.040

49. Alvarez-Aznar A, Martínez-Corral I, Daubel N, Betsholtz C, Mäkinen T, Gaengel K. Tamoxifen-Independent Recombination of Reporter Genes Limits Lineage Tracing and Mosaic Analysis Using CreER(T2) Lines. Transgenic Res (2020) 29:53-68. doi: 10.1007/s11248-019-00177-8

50. Rodriguez M, David CS. Demyelination Induced by Theiler's Virus: Influence of the H-2 Haplotype. J Immunol (1985) 135:2145-8.

51. Rodriguez M, Leibowitz J, David CS. Susceptibility to Theiler's Virus-Induced Demyelination. Mapping of the Gene Within the H-2D Region. J Exp Med (1986) 163:620-31. doi: 10.1084/jem.163.3.620

52. Clatch RJ, Melvold RW, Miller SD, Lipton HL. Theiler's Murine Encephalomyelitis Virus (TMEV)-Induced Demyelinating Disease in Mice Is Influenced by the H-2D Region: Correlation With TEMV-Specific DelayedType Hypersensitivity. J Immunol (1985) 135:1408-14.

53. Howe CL, Lafrance-Corey RG, Sundsbak RS, Lafrance SJ. Inflammatory Monocytes Damage the Hippocampus During Acute Picornavirus Infection of the Brain. J Neuroinflamm (2012) 9:50. doi: 10.1186/1742-2094-9-50

54. Chhatbar C, Prinz M. The Roles of Microglia in Viral Encephalitis: From Sensome to Therapeutic Targeting. Cell Mol Immunol (2021) 18:250-8. doi: 10.1038/s41423-020-00620-5

55. Funk KE, Klein RS. CSF1R Antagonism Limits Local Restimulation of Antiviral CD8(+) T Cells During Viral Encephalitis. J Neuroinflamm (2019) 16:22. doi: 10.1186/s12974-019-1397-4

56. Lei F, Cui N, Zhou C, Chodosh J, Vavvas DG, Paschalis EI. CSF1R Inhibition by a Small-Molecule Inhibitor Is Not Microglia Specific; Affecting Hematopoiesis and the Function of Macrophages. Proc Natl Acad Sci USA (2020) 117:23336-8. doi: 10.1073/pnas.1922788117
57. Waltl I, Käufer C, Gerhauser I, Chhatbar C, Ghita L, Kalinke U, et al. Microglia Have a Protective Role in Viral Encephalitis-Induced Seizure Development and Hippocampal Damage. Brain Behav Immun (2018) 74:186-204. doi: 10.1016/j.bbi.2018.09.006

58. Moseman EA, Blanchard AC, Nayak D, McGavern DB. T Cell Engagement of Cross-Presenting Microglia Protects the Brain From a Nasal Virus Infection. Sci Immunol (2020) 5(48):eabb1817. doi: 10.1126/sciimmunol.abb1817

59. Elmer BM, McAllister AK. Major Histocompatibility Complex Class I Proteins in Brain Development and Plasticity. Trends Neurosci (2012) 35:660-70. doi: 10.1016/j.tins.2012.08.001

60. Ljunggren HG, Karre K. In Search of the 'Missing Self: MHC Molecules and NK Cell Recognition. Immunol Today (1990) 11:237-44. doi: 10.1016/01675699(90)90097-S

61. Lee H, Brott BK, Kirkby LA, Adelson JD, Cheng S, Feller MB, et al. Synapse Elimination and Learning Rules Co-Regulated by MHC Class I H2-Db. Nature (2014) 509:195-200. doi: 10.1038/nature13154

62. Kim JV, Kang SS, Dustin ML, McGavern DB. Myelomonocytic Cell Recruitment Causes Fatal CNS Vascular Injury During Acute Viral Meningitis. Nature (2009) 457:191-5. doi: 10.1038/nature07591

63. Howe CL, LaFrance-Corey RG, Goddery EN, Johnson RK, Mirchia K. Neuronal CCL2 Expression Drives Inflammatory Monocyte Infiltration Into the Brain During Acute Virus Infection. J Neuroinflamm (2017) 14:238. doi: 10.1186/s12974-017-1015-2

64. Rustenhoven J, Drieu A, Mamuladze T, de Lima KA, Dykstra T, Wall M, et al. Functional Characterization of the Dural Sinuses as a Neuroimmune Interface. Cell (2021) 184:1000-16.e1027. doi: 10.1016/j.cell.2020.12.040

65. Kirby L, Jin J, Cardona JG, Smith MD, Martin KA, Wang J, et al. Oligodendrocyte Precursor Cells Present Antigen and Are Cytotoxic Targets in Inflammatory Demyelination. Nat Commun (2019) 10:3887. doi: 10.1038/s41467-019-11638-3

66. McDole JR, Danzer SC, Pun RY, Chen Y, Johnson HL, Pirko I, et al. Rapid Formation of Extended Processes and Engagement of Theiler's Virus-Infected Neurons by CNS-Infiltrating CD8 T Cells. Am J Pathol (2010) 177:1823-33. doi: 10.2353/ajpath.2010.100231

67. Salvioni A, Belloy M, Lebourg A, Bassot E, Cantaloube-Ferrieu V, Vasseur V, et al. Robust Control of a Brain-Persisting Parasite Through MHC I Presentation by Infected Neurons. Cell Rep (2019) 27:3254-68.e3258. doi: 10.1016/j.celrep.2019.05.051

68. Dulken BW, Buckley MT, Navarro Negredo P, Saligrama N, Cayrol R, Leeman DS, et al. Single-Cell Analysis Reveals T Cell Infiltration in Old Neurogenic Niches. Nature (2019) 571:205-10. doi: 10.1038/s41586-019-1362-5

Conflict of Interest: The authors declare that the research was conducted in the absence of any commercial or financial relationships that could be construed as a potential conflict of interest.

Publisher's Note: All claims expressed in this article are solely those of the authors and do not necessarily represent those of their affiliated organizations, or those of the publisher, the editors and the reviewers. Any product that may be evaluated in this article, or claim that may be made by its manufacturer, is not guaranteed or endorsed by the publisher.

Copyright (๑) 2021 Goddery, Fain, Lipovsky, Ayasoufi, Yokanovich, Malo, Khadka, Tritz, Jin, Hansen and Johnson. This is an open-access article distributed under the terms of the Creative Commons Attribution License (CC BY). The use, distribution or reproduction in other forums is permitted, provided the original author(s) and the copyright owner(s) are credited and that the original publication in this journal is cited, in accordance with accepted academic practice. No use, distribution or reproduction is permitted which does not comply with these terms. 